\title{
An Introduction to Social Choice ${ }^{1}$
}

\author{
Maxwell L. Stearns ${ }^{2}$
}

\begin{abstract}
Social choice studies the differing implications of the concept of rationality (or transitivity) for individuals versus groups under specified conditions and the significance of these differences in various institutional decision making contexts. This introductory chapter on social choice for the Elgar Handbook on Public Choice (Elgar Publishing Company, Dan Farber and Anne O'Connell, editors), introduces the basic framework of social choice, considers the implications of social choice for various legal and policy contexts, and provides a framework for evaluating a range of normative proposals grounded in social choice for reforming lawmaking institutions.

After a brief introduction, part II introduces the following concepts: cycling, the median voter theorem, the Condorcet criterion, path dependence, agenda setting, minimum winning coalitions, multipeakedness, dimensionality, symmetry and Arrow's Theorem. This part then describes several notable voting protocols that have been offered in the literature to ameliorate identified deficiencies in aggregating collective preferences, including Borda Counts, Coombs Voting, Hare Voting (or Single Transferable Voting), Copeland Voting, Plurality Voting and Approval Voting. Part III presents prominent normative proposals advanced by legal scholars relying upon, or calling into question, the discipline of social choice, including proposals to change electoral voting procedures; to modify doctrines affecting judicial deference to legislative bodies; and to alter various voting protocols in legislatures and appellate courts, including most notably the Supreme Court. Part IV will rely upon social choice to present a framework for reassessing several of the normative proposals described in part III, along with some of the critical commentary. This part recasts social choice, and in particular Arrow's Theorem, into a set of positive tools that can be used to respond to some of these proposals and to provide insights into how various institutions operate individually and in combination with other lawmaking institutions. The analysis explains the important role of institutional complementarity in improving the quality and rationality of institutional outputs. This part will also introduce several related concepts including the fallacy of composition, the isolation fallacy, and the nirvana fallacy, and apply these concepts to the various proposals and responses considered in part III. Part V revisits Arrow's Theorem and uses the rationality and fairness criteria as a means through which to compare institutions, with a particular focus on Congress and the Supreme Court. The chapter concludes with some suggestions for future social choice research related to law and lawmaking institutions.
\end{abstract}

I. Introduction

The study of social choice grows out of a deceptively simple insight. While economic theory assumes as a condition of rationality that individuals hold transitive preference orderings 
(A preferred to B preferred to $\mathrm{C}$ implies A preferred to $\mathrm{C}$ ), social choice reveals that the transitivity assumption cannot extended to groups of three or more individuals selecting among three or more options through a method of unlimited majority rule. (Riker 1982, p. 100; Stearns 1994, pp. 1221-22). This stunningly simple insight - that the preferences of group members sometimes cycle over options such that ApBpCpA, where p means preferred to by simple majority rule-enjoys an impressive pedigree, dating to two French philosophers writing contemporaneously with the founding and constitutional framing periods in the United States. (Stearns 1994, pp. 1221-24; McLean \& Urken 1992, p. 445, 453-55). Since the 1950s, social choice has generated a rich literature that boasts a prominent Nobel Prize in Economics for Arrow’s Impossibility Theorem, or simply Arrow's Theorem. Perhaps more importantly for present purposes, social choice now forms the basis of a growing legal literature that studies the nature and competence of institutions, including elections, legislatures, courts, and agencies or bureaus.

The legal literature relying upon social choice is rich and varied. Some scholars have relied upon social choice to advance normative proposals to change electoral voting procedures and decision making processes in legislatures and courts. Other scholars have taken a skeptical approach, calling into question the normative foundations of social choice and thus its relevance to various legal contexts. And finally, some have used social choice itself to reinforce our understandings of existing institutional lawmaking processes, thus transforming what started as a normative economic discipline into a positive set of analytical tools capable of explaining important doctrinal anomalies and other seemingly peculiar features of our lawmaking processes.

This chapter proceeds as follows. Part II will introduce several key social choice concepts, using descriptive and visual aids, and avoiding complex mathematical presentations. 
The concepts include cycling, the median voter theorem, the Condorcet criterion, path dependence, agenda setting, minimum winning coalitions, multipeakedness, dimensionality, symmetry and Arrow's Theorem. This part will also briefly describe several notable voting protocols that have been suggested to ameliorate some of the difficulties associated with aggregating collective preferences. These include Borda Counts, Coombs Voting, Hare Voting (or Single Transferable Voting), Copeland Voting, Plurality Voting and Approval Voting. While this chapter will introduce additional concepts as needed to explain various scholarly proposals, these materials lay the essential foundation.

Part III will briefly summarize some prominent normative proposals advanced by legal scholars relying upon, or calling into question, the discipline of social choice. These include proposals to change electoral voting; to modify doctrines affecting judicial deference to legislative bodies; and to alter various voting protocols in legislatures and appellate courts, including most notably the Supreme Court. This part also describes the work of notable scholars who have viewed these and similar proposals skeptically on various normative grounds.

Part IV will rely upon social choice to present a framework for reassessing several of the normative proposals described in part III, along with some of the critical commentary. This part recasts social choice, and in particular Arrow's Theorem, into a set of positive tools that can be used to respond to some of these proposals and to provide insights into how various institutions operate individually and in combination with other lawmaking institutions. ${ }^{3}$ The analysis explains the important role of institutional complementarity in improving the quality and rationality of institutional outputs. This part will also introduce several related concepts including the fallacy of composition, the isolation fallacy, and the nirvana fallacy, and apply these and related concepts to the various proposals and responses considered in part III. Part V 
revisits Arrow's Theorem and uses the rationality and fairness criteria as a means through which to compare institutions, with a particular focus on Congress and the Supreme Court. The chapter concludes with some suggestions for future social choice research related to law and lawmaking institutions.

II. The problem of social choice

A. Cyclical preferences, the Condorcet criterion, and agenda setting

We begin with the so called paradox of voting, namely that a group of persons each holding rational (transitive) preference orderings, can cycle (thus revealing a collective intransitivity) when aggregating preferences in a regime characterized by unlimited majority rule. To illustrate, imagine three persons choosing among three options ABC. The options can represent virtually anything, including political platforms, the amount to spend on a particular public project, or even something as trivial as the flavor of an ice cream cake. We begin with the general assumption of rationality that A preferred to B preferred to $\mathrm{C}$ implies A preferred to $\mathrm{C}$. If, when buying ice cream, Alice prefers coffee to chocolate and chocolate to vanilla, most would infer that she also prefers coffee to vanilla. The assumption does not foreclose Alice from ever selecting vanilla even if coffee is available, as she might if she had coffee several nights in a row, or even from changing her tastes over time. But if asked whether she generally prefers coffee or vanilla, in light of her other preferences it would seem odd if she chose vanilla.

Social choice theory reveals that this simple assumption respecting individual rationality cannot be extended to groups of three or more who seek to transform individually rational preferences into transitive group orderings. To illustrate, assume that three persons (represented as $\mathrm{P} 1, \mathrm{P} 2$ and $\mathrm{P} 3$ ), are choosing among three options, $\mathrm{ABC}$, or alternatively that each person represents a constituency in a larger assembly such that any two-group combination contains 
sufficient votes to form a majority. Assume that after the members disclose their first choices, they discover that no option is a first choice majority winner. The participants then candidly disclose their ordinally preference rankings from most-to-least preferred as follows:

P1: ABC

P2: BCA

P3: $\mathrm{CAB}$

The members then experiment with a series of pairwise votes to see if a satisfactory outcome emerges. Assume that each member votes consistently with his or her expressed ordinal ranking in each direct comparison. As explained below, this satisfies the condition of Independence of Irrelevant Alternatives in Arrow’s Theorem. ${ }^{4}$

Based upon these assumptions, the voting regime yields the following results: ApB (P2 losing), BpC (P3 losing), but CpA (P1 losing), thus generating the cycle, ApBpCpA, where p means preferred to by simple majority rule. Whereas $\mathrm{P} 1$, who prefers $\mathrm{A}$ to $\mathrm{B}$ and $\mathrm{B}$ to $\mathrm{C}$ also prefers A to $\mathrm{C}$, thus satisfying rationality, the analysis reveals that with the stated group preferences, transitivity fails for the group as a whole.

This example illustrates the voting paradox, also called the Condorcet paradox, after a French philosopher who described it in an essay in 1789. (Stearns 1994, p. 1221). Simply put, the paradox is that transitivity, assumed to be a basic tenet of individual rationality, cannot be assumed for groups of three or more individuals selecting among three or more options using an unlimited system of majority rule.

In addition to describing the paradox of voting, Condorcet proposed an important, albeit partial, solution to the problem concerning how to transform individual preferences lacking a first choice majority winner into normatively defensible social outcome. Condorcet maintained that absent a first choice majority candidate, that option that would defeat all others in direct 
comparisons should be selected as best. (Riker 1982, p. 100; Stearns 1994, pp. 1253-54).

To illustrate, consider the following slightly modified set of group preferences:

P1: ABC

P2: BCA

P3: CBA

Other than changing P3's second and third ordinal ranking from CAB to CBA, the preferences remain as before and once again there is no first choice majority candidate. Now apply Condorcet's proposed method. This time B defeats A (P1 losing) and B defeats C (P3 losing). The choice between A and C is irrelevant (C wins, with P1 losing) because option $\mathrm{B}$, the Condorcet winner, prevails against both alternatives in direct comparisons by majority rule. Institutions that ensure that available Condorcet winners prevail are said to satisfy the Condorcet criterion.

Scholars have identified the Condorcet criterion as an important benchmark in evaluating the decision making competence of institutions. (Riker 1982, p. 100; Stearns 1994, pp. 1252-57; Levmore 1989, pp. 994-96). Institutions that fail to ensure that available Condorcet winners prevail thwart democratic norms in the sense that some majority disfavors the selected outcome to an available alternative. As Professor William H. Riker observed, 'when an alternative opposed by a majority wins, quite clearly the votes of some people are not being counted the same as other people’s votes.' (Riker 1982, p. 100).

As a result of two notable defects, however, some important institutions employ decision making rules that fail to adhere to the Condorcet criterion. First, as seen in the illustration with cyclical preferences (ABC, BCA, CAB), not all group preferences contain a Condorcet winner. Absent a Condorcet winner, rules that satisfy the Condorcet criterion generally produce an intransitivity or voting cycle (ApBpCpA). ${ }^{5}$ (Stearns [2000] 2002, pp. 46-49). A cycle implies 
that for any possible outcome, another is preferred in a regime of direct pairwise comparisons by simple majority rule. Because this result holds for all possible outcomes, when participants hold such preferences, rules that satisfy the Condorcet criterion fail to guarantee a stable, or at least a socially significant, outcome.

We can think of rules that satisfy the Condorcet criterion as having the characteristic feature of unlimited majority veto and thus as possessing important attributes, both positive and negative, of majority rule. Pairwise comparisons remain subject to majority vote unless and until there is no longer a set of thwarted majority preferences. When group preferences cycle, however, some majority always prefers another outcome.

Although groups possessing cyclical preferences cannot select a winner without thwarting the preferences of a majority in a potential pairwise comparison, this does not imply that participants forever engage in fruitless binary comparisons. Rather, assuming the group does not elect inaction (thus 'choosing' the status quo ante), the cycle manifests itself in whichever outcome is ultimately chosen. This follows from the characteristic features of rules that satisfy the Condorcet criterion.

Rules that meet this criterion permit the same number of pairwise contests as options. In contrast, when decision rules limit pairwise contests relative to available options and when member preferences cycle, assuming sincere voting, the substantive outcome will turn on the order in which options are voted. Non-Condorcet rules thus risk grounding outcomes in the order, or 'path,' of voting. Path dependent outcomes can be stable and perhaps even predictable, for example if everyone votes sincerely despite knowing the intentions of the agenda setter. (Shepsle 1992, p. 242 n.6). At the same time, however, path dependent outcomes thwart the preferences of at least one majority that would have preferred an alternative outcome in a 
suppressed binary comparison.

To illustrate, consider once again the illustration with intransitive preferences (ABC, $\mathrm{BCA}, \mathrm{CAB}$ ). If we permit only two votes over the three options, and if we assume that members vote sincerely, then we will induce a path toward a determinate result. If we begin with A versus B (A wins) followed by C versus A (C wins), C prevails. Only by bringing back option B, which was defeated in the first round, and pitting it against option $\mathrm{C}$ do we formally reveal the cycle ВрСрАрВ. If we knew the ordinally ranked preferences in advance of voting, we could intuit that option C thwarted the majority preferences of P1 and P2, who form a majority that prefers B to C. Thus, while path dependence leads to a stable outcome, with full disclosure or the subsequent discovery of suppressed preferences we can discover an imbedded cycle. Of course participants will not always have the information from which to infer a cycle and for this reason non-Condorcet rules give the appearance of majority support for the eventual outcome. After all, the chosen outcome followed a series of separate majority votes, thus lending it the appearance of normative legitimacy even though with more information, or perhaps a different voting procedure, voters might have called the outcome's social significance into question.

Path dependence is the flipside of agenda setting. Assume that participants vote sincerely according to their ordinal preferences (ABC, $\mathrm{BCA}, \mathrm{CAB}$ ) and that the voting rule permits only two pairwise votes for the three options and thus for the three potential binary comparisons (AB, BC, CA). By permitting fewer binary comparisons than options, this regime empowers the agenda setter to determine the outcome. By sequencing votes so that the option that would defeat the agenda setter's first choice is itself defeated in the first round of voting, assuming once again that participants vote sincerely, she is able to produce a voting path that leads directly to her first choice. ${ }^{6}$ Not surprisingly, one strand of social choice scholarship focuses on how to limit agenda 
setting or path dependent outcomes in various law making contexts. ${ }^{7}$

The second notable defect of rules meeting the Condorcet criterion, a defect that once again applies generally to majority rule, is the failure to account for the intensities of preference. Consider once more the preferences ABC, BCA, CBA, yielding B as a Condorcet winner. It is possible that despite the apparent consensus for that option the only participant who cares about the issue is $\mathrm{P} 3$, and that she greatly prefers option $\mathrm{C}$ while she only slightly prefers option $\mathrm{B}$ to option A. If, despite their ordinal rankings, P1 and P2 are nearly indifferent as to how this issue is resolved, selecting the Condorcet winner, B, might prove a socially inferior outcome to option C. Institutions that place substantial weight on degrees of preference, including legislatures, facilitate a regime of vote trading, or logrolling. This allows legislators to commodify preferences, rather than merely to rank them ordinally. ${ }^{8}$

Having considered the paradox of voting and the Condorcet criterion, we now briefly turn to Arrow's Impossibility Theorem, or simply Arrow's Theorem. This theorem has been aptly characterized a generalization of the paradox of voting. (Riker 1982, p. 317). While this chapter will provide a more detailed description of the underlying conditions below, this brief introduction will help to place the prior discussion in a broader context.

B. A first look at Arrow's Theorem ${ }^{9}$

Just as the Condorcet criterion generalizes majority rule, Arrow's Theorem generalizes the voting paradox. (Riker 1982, p. 116). The theorem demonstrates that any rule that one might offer to 'solve' the potential impasse that results when preferences cycle risks violating some fundamental attribute of fair and democratic decision making. (Arrow 1951; Arrow 1963). Arrow posited a set of conditions, which William Vickrey recast as four fairness conditions in a simplified version of the proof (Vickrey 1960, pp. 507-09; Mueller 2003, p. 583), and proved 
that no institution can simultaneously satisfy those conditions while also guaranteeing the ability to translate the individual preferences of members into rational, or transitive, orderings. ${ }^{10}$ (Stearns 1994, pp. 1247-52). Arrow's Theorem reveals an inevitable tension that collective decision making bodies confront between promoting rational (transitive) outcomes and adhering to fair democratic norms.

The theorem proves an inability to simultaneously guarantee transforming individually rational preference orderings into transitive outcomes for the group as a whole while adhering to the following fairness conditions: (1) range: the collective decision making rule must select its outcome in a manner that is consistent with the members' selection from among all conceivable ordinal rankings over three available alternatives; (2) independence of irrelevant alternatives: in choosing among paired alternatives, participants are assumed to decide solely based upon the merits of those options and without regard to how they would rank options that might be introduced later; (3) unanimity: if a change from the status quo to an alternate state will improve the position of at least a single participant without harming anyone else, the decision making body must so move; and (4) nondictatorship: the group cannot consistently vindicate the preferences of a group member against the contrary will of the group as a whole. (Stearns [2000] 2002, pp. 84-94).

Because Arrow's Theorem proves that no institution can simultaneously ensure transitive outputs and satisfy the specified fairness criteria, it exposes inevitable tradeoffs between the need for certain and stable outcomes on the one hand, and rule making features designed to ensure fair collective processes on the other. One critical implication of Arrow's Theorem, for example, is in exposing an inevitable tradeoff between rules that ensure transitive outputs and rules that prevent minorities from exerting power disproportionate to their numbers. ${ }^{11}$ If unlimited majority 
veto has the potential to block stable outcomes as a result of underlying cycling preferences, the sole means of ensuring stable outcomes might be to vest ultimate decisional responsibility in a minority of the group as a whole. It is for that reason that collective decision making difficulties implicate not just the voting paradox that Condorcet described, but more generally the rationality and fairness conditions that Arrow's Theorem proves at least theoretically in conflict.

C. Peaks, dimensionality, and symmetry (or exploring the intuition for when preferences cycle)

In effect, Arrow's Theorem proves that the difficulties that cycling preferences pose cannot be avoided costlessly. The theorem itself, however, does not speak to the frequency of group preferences that cycle or to the conditions likely to generate cycling preferences. This part considers the nature of the conditions that conduce to cyclical or well behaved (or stable) preference orderings. We start with two alternative framings of the problem of cycling preferences, and later explain that ultimately both framings express the same underlying intuition in different, yet complementary, terms.

\section{A group with well-tamed preferences}

Imagine an assembly with three members or three coalitions such that any two form a simple majority. The assembly seeks to allocate funds for a federal bailout of a given industry during a recession. The proposed amounts, in increments of $\$ 100$ billion, are 5,7 , and 9 , each of which is the first choice of one of the three members. Intuitively we might imagine that if each legislator, P1, P2 and P3, holds a different first choice preference, 5, 7, and 9 respectively, P1 and P3 who most prefer the extreme positions of 5 or 9, will prefer the intermediate position, 7, to the opposite extreme, 9 or $5 .^{12}$ If this assumption holds, then in a regime of incremental voting that starts at either extreme and works its way from the bottom up or from the top down, the 
members will converge upon the middle allocation, 7. Regardless of the starting point, each increment gains one vote until a majority forms. ${ }^{13}$ We can extend this insight to embrace larger numbers of voting options provided that the participants rank the options along a single dimensional continuum. When preferences satisfy this condition, either top-down or bottom-up voting locates the median option, or Condorcet winner.

The same underlying logic explains the well known median voter theorem. ${ }^{14}$ Assume that voter preferences align along a single dimensional liberal to conservative scale and that there are two candidates, one very liberal and one very conservative. The theorem predicts that the candidates will rationally be motivated to move toward the ideological position of the hypothetical median voter in an effort to gather votes. Assuming universal voting and that the liberal candidate remains ever so slightly to the left of the conservative candidate, holding all else constant, voters on both sides of the spectrum will have an incentive to support the candidate whose ideological position is closest to their own. A very liberal voter will thus prefer even a watered down liberal candidate to the now slightly more conservative candidate, while a very conservative voter will prefer even a watered down conservative candidate to the now slightly more liberal candidate. ${ }^{15}$

Returning to the bailout hypothetical, even if the legislators hold well tamed preferences, it is possible that the voting regime might miss available an Condorcet winner. This is increasingly possible if the legislators lack complete information regarding the preferences of other members. Assume that instead of voting based upon ordinal sequencing (whether top down or bottom up) the institution permits the committee chair to order votes in any order she prefers. Further assume that the chair hopes to achieve the maximum allocation of 9 . She might first present the middle position, 7, and then following its defeat (with both who prefer the more 
extreme positions prevailing and hoping that their preferred option is voted last), present 5 , which will also be defeated (with those preferring 7 or 9 prevailing). The participants would then vote 9 up or down, with the possible result of approval if the only remaining alternative is not to proceed with the bailout at all. By instead adopting an incremental voting rule, the assembly disciplines the chair and ensures itself the median outcome, 7. With knowledge of the sequencing in advance, the loser in the first round (favoring either 5 or 9) anticipates that failing to approve 7 will produce the opposite extreme, and least preferred, outcome.

The intuition about the risk of agenda setting by a committee chair proves helpful in explaining the evolution of competing parliamentary rules of procedure developed in the nineteenth century (Levmore 1989, pp. 986-90). In his study of parliamentary rules, Levmore demonstrated that when legislative assemblies vote on relatively few options that likely include a Condorcet winner, rules gravitate toward motion and amendment, which is generally capable of finding it. In contrast, when the number of options increases or when there is a risk that a committee chair will strategically present options to benefit from agenda setting, the rules tend to shift in the direction of succession voting, which bases voting on the order in which motions are raised, rather than on the order in which the chair presents them for consideration. And when larger numbers of options are likely to include a Condorcet winner, for example, when choosing discrete alternatives along a common spectrum, the rules generally impose a logical order to the voting such as low to high or early to late. As seen in the bailout proposal example, this regime both disciplines the chair and restores the probability of finding a Condorcet winner.

2. Peaks and dimensionality

While the preceding bailout plan illustration depicted preferences resting along a single dimensional continuum thus generating a preferred median outcome, or Condorcet winner, not 
all group preferences align in this neat manner. As a result, it is possible to modify the assumptions in a manner that produces cycling preferences. ${ }^{16}$ This illustration will demonstrate that for some group preferences, what appears as a common normative dimension fails to capture the essential stakes. This intuition can be expressed in two complementary ways.

We begin with the concept of mutipeakedness, which allows us to depict more complex preference configurations along a single dimensional continuum. Imagine that one assembly member ranks her preferences as follows: (1) highest option; (2) lowest option; (3) middle option. This is less counterintuitive than it first appears. Assume once again that the assembly is selecting bailout amounts in increments of $\$ 100$ billion of 5,7 , and 9 for a given industry and that these are the only available options. Imagine that P1 is a fiscal conservative who is generally skeptical of Keyesian economic policies, and thus ranks her preferences 5, 7, 9. P2 supports the bailout, but prefers an intermediate allocation as his first choice so that the assembly holds some funds in reserve for the next failing industry. P2 ranks the options 7,9,5. Finally, P3 favors an aggressive bailout plan but is persuaded that anything short of the maximum allocation of 9 will not succeed in allowing the targeted industry to remain viable, and thus will waste taxpayer expenditures. P3 ranks his preferences 9, 5, 7.

While the proposed expenditures can be cast along a unidimensional continuum, representing the allotted amounts for the bailout, unlike P1 and P2, whose preferences are each cast on a single peaked curve (5,7,9 and 7,9,5 respectively), legislator P3, who least prefers the middle position, produces a ranking produces two peaks at the extreme ends and a valley in the middle $(9,5,7)$. This seemingly odd ranking implies that P3 assesses the choices along an additional analytical dimension not captured by the incremental values.

[Insert and adapt Figure 1 about here] 
Figure 1 lists discrete measures of utility as a proxy for the values the legislators place on each proposed allocation. With these preferences, a series of direct pairwise comparisons reveals that separate majorities prefer allocations of 7 to 9 and 9 to 5 , but 5 to 7 , thus producing the cycle 7p9p5p7.

While the preceding discussion depicts cyclical preferences along a single normative dimension (based upon the chronology of adjournment dates) with one member holding multipeaked preferences, the same preferences can be expressed as three sets of single peaked curves cast across two normative dimensions. ${ }^{17}$ (Ordeshook 1986, pp. 164-65, Stearns [2000] 2002, p. 74). For the three decision makers, the selection of bailout allocation implicates two issues rather than one, first, whether or not to pursue a liberal Keynesian policy, and second, whether to vote based upon the probable effectiveness of the specific allocation proposal for the industry seeking the bailout.

Table 1 depicts each proposed budgetary allocation based upon how it fits within the resolution of these two policy dimensions:

\begin{tabular}{|l|l|l|}
\hline & No Minimal Allocation Required & Minimum Allocation Required \\
\hline Reject Keynesian Policy & 5 & \\
\hline Accept Keynesian Policy & 7 & 9 \\
\hline
\end{tabular}

Table 1: Bailout Allocations in Two Dimensions

Each specific allocation reflects a combined judgment respecting two separate issues. Option 5 reflects a preference to avoid a Keynesian fiscal policy and a rejection of the need for a minimal threshold allocation for an effective bailout plan. Option 7 reflects a preference for Keynesian fiscal policy and a rejection of the need for a minimal threshold allocation for an effective bailout 
plan. Option 9 reflects a preference for Keynesian fiscal policy and an insistence upon a minimal threshold allocation for an effective bailout plan.

Given these combined preferences packages represented by each individual option, we can now recast the preferences of each legislator. Based upon the prior discussion, P1, the fiscally conservative who does not believe that a specific minimum expenditure is required for effectiveness, ranks her options 5,7,9, seeking to spend the minimum amount possible on the bailout plan. While P2 is not a fiscal conservative, he also does not believe that there is any required minimum allocation required for some degree of effectiveness, although he does prefer to avoid the minimal allocation. He therefore ranks the options 7,9,5. Finally, P3, who is also not a fiscal conservative, believes that a minimum of 9 is required for the plan to be effective. He ranks the options 9,5,7 because absent the threshold minimum of 9 , he believes that the plan is likely to fail and thus prefers not to waste taxpayer resources. By expanding the issue space to accommodate both of these choice dimensions, we can now recast the three sets of preferences into single peaked set of preferences cast along two analytical dimensions.

\section{[Insert Figure 2 about here]}

Figure 2, which again lists discrete measures of utility as a proxy for the values the legislators place on each proposed allocation, ${ }^{18}$ casts the preferences over the three options across the relevant two dimensions. The result is that each member's preferences appear as a single peaked curve spread over two dimensions. To visualize this, imagine cutting the figure from the page and rolling it into a tube. The result is three continuous sets of single peaked preferences curves over the now two dimensions, reflecting the policy choices depicted in Table 1. The important point for our purposes is that the two graphic depictions represented in Figure 1 (multipeakedness across a unidimensional issue spectrum) and Figure 2 (single peakedness 
across a multidimensional issue spectrum) each capture the same underlying insight.

This framing helps to demonstrating the nature of the conditions that give rise to cycling preferences. When the choices presented not only undermine support for a single first choice option, but also invite participants to weigh those options based upon additional normative criteria, meaning frames of references that the initial set of policy options did not implicate, then it is increasingly likely that the participants' preferences no longer conduce toward a common median preferred outcome. A median position implies a common normative scale of measurement. As the number of options increases, so too does the number of normative spectra along which those options might be assessed. And as the number of normative spectra increases, the likelihood that the members will contain such a common preferred outcome correspondingly diminishes. Even so, not all choices that implicate two or more issue dimensions will necessarily produce the sort of multidimensionality required to produce a cycle. To see why, we must now introduce one more pair of concepts, namely symmetry and asymmetry.

3. Symmetry and assymetry

Cycling is not inevitable every time group decision making implicates more than a single dimension of choice. Instead, only those preferences that also possess the characteristic feature of asymmetry generate the sort of multidimensionality conducive to a cycle. The more general case of preferences in two issue dimensions, those that possess the characteristic feature of symmetry, do not cycle. (Stearns [2000] 2002, pp. 75-77; Stearns 1999, pp. 123-28, 139-53).

To illustrate, let us now change our assumptions about the preferences of P3. In this hypothetical, while P3 is still not a fiscal conservative and while he continues to believe that an effective plan requires a minimum allocation of 9 , he now is willing to risk the moderate allocation of 7 as a second choice, rather than vote for the lowest allocation of 5 , which is even 
less likely to succeed. The resulting preferences are now 9,7,5. As before, the preferences of P1 are 5,7,9 and the preferences for P2 are 7,9,5. While the changed assumptions still implicate more than one issue of choice, whether to pursue a fiscally conservative policy and whether to target the allocation based upon the anticipated effectiveness for the specific industry, the revised ordering effectively flattens the dimensionality in a manner that avoids a cycle and instead conduces to a stable median outcome. As a result, we can now cast the combined preferences along a single dimensional scale, corresponding to the proposed amounts, even though the legislators select their preferences based upon differing issue considerations.

P1 bases her ordinal ranking primarily on a policy of fiscal conservatism in general, while P3 bases his ordinal ranking on the specific likelihood that a given allocation will prove effective or ineffective. Even with more than a single approach to framing the inquiry into the proper bailout amount, the modification of P3's preferences restores the earlier well tamed preferences. In this example, P1 prefers 5,7,9; P2 prefers 7,9,5; and P3 prefers 9,7,5. In this example, depicted in Figure 3, P1 and P3 express symmetrical preferences over the two issues such that they form an ' $\mathrm{X}$ ' over 7 as the dominant middle position, or Condorcet winner.

\section{[Insert Figure 3 about here]}

In fact, the same result predominates whether P2 ranks his overall preferences 7,9,5 or 7,5,9. The symmetrical nature of the preferences for P1 and P3 in Figure 3 (in contrast with the asymmetrical nature of the preferences of P1 and P3 in Figure 1) ensures that regardless of P2's second and third ordinal preferences, option 7 will prevail. The preferences expressed in both Figures 2 and 3 can be characterized as resting along two issue dimensions. And yet, with the symmetrical preferences centering on the median outcome of 7 , the two issue dimensions flatten into one meaningful dimension of social choice, thus avoiding intransitive group orderings. 
As the preceding analysis demonstrates, increasing the number of options and decision makers can affect the not merely the framing of underlying issues, but also the meaningful dimensionality of choice. As a result, social choice scholars have studied the frequency of cycling preferences (or of the absence of a Condorcet winner) as a function of both the number of options and group size. Table 2, taken from William H. Riker, is illustrative:

\section{[Insert Table 2 about here]}

The preceding analysis explains the nature of the conditions that conduce to stable or cyclical preferences. Not surprisingly, scholars have attempted to improve the quality of decision making by suggesting various voting protocols intended to reduce the difficulties that arise when collective preferences have the potential to cycle. The next subpart briefly reviews several common voting regimes along with some of the more prominent proposed voting rules, and explains the respective strengths and weaknesses of each rule.

D. Formal voting protocols

The following proposed voting protocols are intended to minimize the practical difficulties associated with arriving at a meaningful social choice when group preferences are susceptible of cycling. Some of these protocols have ancient roots, while others are of more recent vintage. In addition, some protocols find reflection in concrete decision making settings, while others are administratively impractical and for that reason have remained of primarily theoretical interest. Even theoretical regimes have value, however, inasmuch as they allow scholars to isolate those features that render various voting regimes susceptible of meaningful implementation.

1. Majority, plurality rule (with and without runoff), and the narrowest grounds rule (Condorcet revisited) 
The most obvious voting protocol is majority rule, which selects that candidate or option receiving a majority of first choice votes. Despite its intuitive appeal, majority rule suffers the following limitations: (1) not all group preferences contain a first choice majority candidate; and (2) majority rule fails to account for the intensity with which participants hold their preferences. Based upon the preceding analysis, these problems are now familiar. As we have seen, the likelihood of a first choice majority candidate correlates negatively with the number of options. In addition, even if there is a majority winner, it is possible that the majority preferred option fails to reflect the intense stakes for a minority of participants, or conversely the low stakes for a majority of participants.

The concern that simple majority voting procedures might disadvantage discrete minority groups motivated James Madison, in his discussion of the violence of factions, to counsel in favor of bicameralism and presentment before a bill becomes a law. (Madison 1987, pp. 12227). The Supreme Court has extended this intuition, thus incorporating the concern for the intensity of minority interests into its equal protection jurisprudence. Specifically, the Court has suggested lowering the strength of presumptive validity for laws affecting "discrete and insular minorities” (United States v. Carolene Prods. Co., 304 U.S. 144, 153 n.4 (1938)), even assuming that the challenged law was approved consistent with Madison’s “finely wrought” procedures set out in Article I, § 7 (Immigration and Naturalization Serv. v. Chadha, 462 U.S. 919, 921, 951 (1983)), or equivalent state lawmaking procedures.

When there are more than two options and when it is unlikely that any single option is a first choice majority candidate, a common voting process is to select the outcome that receives a plurality of votes, meaning the largest number of votes when no option receives a majority. With only two options, majority rule and plurality rule yield the same outcome. ${ }^{19}$ With many options, 
and barring a tie, plurality rule can locate a winner even if majority rule cannot. The most obvious benefit of plurality rule is its relatively low administrative cost in declaring a winner. Notice, for example, that while legislatures gravitate toward motion and amendment in lawmaking procedures, they shift to plurality rule when selecting among persons to fill committee chairs. (Levmore 1989, pp. 1015-17; Stearns 1994, p. 1265-66 n.173). While plurality rule ensures an outcome (at least absent a tie), it risks missing potential Condorcet winners. Plurality rule provides the voting equivalent of rough justice. It is a quick, but sometimes dirty, way of getting an outcome when the complexity of choices and preferences risk failing to arrive at a meaningful consensus.

In elections with large fields of candidates, for example, plurality rule risks selecting a candidate with loyal minority support even if that candidate is outside the mainstream. One way to reduce this result is through staged plurality elections. This has the benefit of eliminating candidates who do not earn votes above a certain threshold and of matching candidates who survive an early round but who are outside the mainstream against fewer competing candidates in later voting rounds. Plurality with runoff does not ensure that Condorcet winners prevail, but at a minimum it ensures that Condorcet losers, those options that would lose against any alternative in a binary comparison, do not prevail, a result that could obtain in a single staged plurality election. For example, this could occur in an election with three candidates in which A holds $40 \%$ support and B and C split evenly the remaining $60 \%$ of the electorate. If B and C were able to combine their electoral support in the event that one or the other was eliminated for a total of $60 \%$ support, then the result of a single stage election would be to ensure the victory of A, a Condorcet loser. Either B or C would defeat A, 60\% to 40\%, in a direct binary comparison. Not only does plurality voting with a runoff reduce the probability of electing a Condorcet loser, 
but also it improves the probability of selecting a Condorcet winner depending on the number of candidates in the initial field.

In other settings, the suitability of plurality rule turns on the likelihood that the selections will fall along a single dimensional scale. Imagine, for example, options one through nine, each representing a proposed allocation for a public project, where each proposal receives equal support and where all voters hold single peaked preferences. As we have already seen, in this context, the median outcome, or Condorcet winner, is five. If one member who initially preferred an extreme position, say nine, is persuaded to join forces with the person who most prefers the second most extreme position, eight, then if everyone else votes sincerely, eight will emerge victorious under plurality rule, with two votes to every other option's vote of one, thus defeating option five, the Condorcet winner.

Within the Supreme Court, which has nine justices, the possibility that plurality rule might select an extreme outcome is considerable. Consider, for example, a case in which the Court fails to achieve a majority outcome, and in which the opinions consistent with the judgment are split into two separate groupings of two and three, thus forming a majority of five for the Court as a whole. In this situation, plurality rule might select a unified dissent (with four votes) as stating the holding. This is obviously an absurd result. One might instead apply plurality voting to the opinions consistent with the judgment, thus selecting the opinion with three votes. This too can produce an absurd result if the three justices embrace a sufficiently extreme view that if forced to choose between the two positions embraced by the votes of four and three respectively, the coalition of two would prefer to side with the dissenting group, elevating it to majority status (but changing the judgment).

The Supreme Court does not apply even this more limited version of plurality rule, which 
like plurality rule more generally, threatens to miss available Condorcet winners. Instead, the Court stages its case resolution rules to first vote in binary fashion on the judgment, and then once that judgment is selected to identify the opinion consistent with the judgment that resolves the case on the narrowest grounds. (Marks v. United States, 430 U.S. 188, 193 (1977); Stearns [2000] 2002, pp. 124-29). In those cases in which the opinions can be cast along a single dimensional scale, or over two dimensions with symmetrical preferences, this combined voting regime- outcome voting and the narrowest grounds rule- has the benefit of both ensuring an outcome and locating the opinion that is the Condorcet winner among available options. (Stearns [2000] 2002, pp. 127-28).

To illustrate, imagine the following stylized presentation of Board of Regents v. Bakke, 438 U.S. 265 (1978), which involved a challenge to a state medical school's affirmative action program taking the form of a racial set aside or quota of sixteen out of one hundred seats. One group of four justices would prohibit state schools of higher education from employing race as a factor in admissions, thus voting to strike down the challenged affirmative action program. Another group of four justices would broadly permit states to use race in this manner, and would sustain even a program that uses race as a quota, thus voting to reject the constitutional challenge. Finally, Justice Powell, standing alone, would permit the use of race, but only if race is not used as a quota, and if instead it is one plus factor among many in a combined admissions process. In this case, applying plurality rule to the opinions consistent with the judgment (striking down the race-based quota) would result in selecting the most conservative position, thus preventing the use of race altogether. The combined regime of outcome voting and the narrowest grounds rule instead resulted in striking down the challenged program, but further allowed Powell to permit the use of race under a narrower set of conditions than those preferred 
by the larger liberal wing of the Court. While it might seem anomalous that a single justice determined the policy concerning affirmative action in a case in which two four-member coalitions declined to embrace his ultimate rationale, social choice provides a basis for this result. The three main opinions in Bakke can effectively be cast along a single dimension, from narrow to broad power to use race, or they can be cast along two dimensions with symmetrical preferences in which those preferring broad use of race and those preferring a total ban on race would each prefer Powell's hybrid solution as a second choice. Either way, Powell's opinion emerges as the median or Condorcet winning outcome. A similar analysis can be used to explain why the jointly authored per curiam opinion in Planned Parenthood v. Casey, 505 U.S. 833 (1992), which modified without overruling Roe v. Wade, 410 U.S. 113 (1973), emerges as the dominant Condorcet winning outcome under the narrowest grounds rule. As these cases illustrate, social choice helps to explain some of the most anomalous, and salient, outcomes of modern constitutional interpretation. ${ }^{20}$

2. Other voting protocols: approval, Borda, Coombs, Hare (single transferrable voting), Copeland

We now turn to a variety of other institutional voting procedures, some of which have been implemented and others of which remain largely theoretical constructs. These include regimes that seek to eliminate options until a cycle no longer is present or various point-driven methods of separating preferences that if listed in strictly ordinal fashion would conduce to a cycle. We begin with relatively familiar regimes and progress toward increasingly theoretical or otherwise impracticable regimes.

Approval voting: Under approval voting, each participant selects a subset of choices he or she deems acceptable from the total slate of candidates or options. Depending on how many 
options are ultimately being selected, the option with the largest number of votes (in addition to those options with the second largest number of votes, etc.) wins. (Mueller 2003, pp. 156-58). As the name suggests, the voter's choice with respect to each option is binary. The voters determine who they approve (or disapprove) with no ordinal rankings, and they cannot cast more than a single vote for any candidate. ${ }^{21}$ This regime affords participants a large range of choice by not foreclosing options, and thus works effectively when participants are seeking a list of acceptable options from a larger list. Familiar illustrations include selecting a group of workshop speakers or paring down a larger list of potential faculty candidates. The downside is that, especially when approval voting is used to select a single option or a small number of options, the regime risks missing available Condorcet winners. The intuition is that because an option might have broad support as to acceptability, it might get the most approval votes even though another option that fewer voters approve would defeat the more widely approved option in a direct pairwise contest.

Borda counting: Assume a field of $n$ options or candidates. Each voter ranks each option from $n$ to 1 , where $n$ represents an integer equal to the total number of candidates, and where voters select $n$ for the most preferred candidate, $n$ minus 1 for the second most preferred candidate, down to 1 for the least preferred candidate. The points for each candidate are then tallied and the candidate with the highest point score is selected. The Borda system, which was proposed in 1770 , operates on a specific logic. By requiring voters to attach discrete integer rankings as a proxy for intensity of preference, the system allows some voters to place distance between potentially cycling options, thus eliminating a good many cycles through a form of commodification or cardinalization of preference.

While Borda counting increases the likelihood of an outcome even when preferences 
cycle, it is nonetheless a blunt tool. The bluntness arises from attaching discrete integers to distance options as a proxy for expressing intensities of preference. In addition, as Dennis C. Mueller notes, the regime invites strategic voting behavior by encouraging participants to rank options that they disfavor but that have broad support substantially lower than they would in a pure merits-based assessment. Mueller observes that if the regimes are implemented in a single round of voting, Borda counts, along with the voting schemes devised by Coombs and Hare, described below, obtain the same voter information, and not surprisingly, therefore exhibit comparable performance. (Mueller 2003, pp. 152-56).

Coombs voting: In this regime, the participants identify their least preferred candidate options and those candidates who the largest number of voters list as lowest are removed. The process is repeated until a victor emerges. (Mueller 2003, pp. 147-48). While this system has the benefit of eliminating Condorcet losers, defined as those candidates who would lose in a direct comparison to all other available candidates in head to head competitions, it does not guarantee that Condorcet winners do prevail. In addition, the regime is difficult to implement. If handled sequentially rather than in a single process, Coombs has the unusual characteristic of requiring voters to express views on their least, rather than most, favored candidates. Perhaps not surprisingly there are few documented applications. That said, the regime might sometimes be used informally as a means of reducing choice sets in relatively informal settings including slating speakers for academic workshops or fielding faculty candidates.

Hare voting (or single transferrable voting): In this regime, each participant identifies the candidate he or she most prefers in a field of candidates. The candidate identified by the fewest voters each round is removed and the process is repeated until a victor emerges. (Mueller 2003, p. 147). The regime is also called transferrable voting or single transferrable voting because the 
participants are sometimes required to provide rankings over all candidates to allow continued removals after each staged election is completed and until a final candidate emerges the winner.

This is a similar system to Coombs, except that rather than using the least preferred by the most participants as the criterion for removal, this uses the least number of most preferred as the criterion for removal. The Hare system has the benefit of assembling voter preferences in a single round that permits continuous progressions of removal in multiple iterations. Because this regime, like the prior two regimes, requires substantial information from voters, specifically rankings over all candidates in the field, it tends to be used in relatively small electoral settings as compared with the United States. The process has been used in some form in such countries as Australia and Ireland, although there is substantial variation in the precise details of each voting system. (Mulroy 1999, p. 1879). It also has been applied in the context of deriving lists for parties in parliamentary systems that are not geographically districted. In this context, party activists are likely to have substantial knowledge about the slate of party candidates that facilitates the necessary rankings.

Within the United States, some academic commentators have proposed adopting a version of Hare voting in various electoral settings. (Richie 2004, pp. 506-12; Cihak 2007, pp. 700-01). One claimed benefit is that in a race with a third party spoiler, for example Ralph Nader in the 2000 presidential election, Hare voting would have facilitated a direct comparison of the two leading candidates, George W. Bush and Al Gore, while still allowing those frustrated with these choices to register a protest vote as a nominal (and later removed) first choice. If we assume that Nader was more liberal than Gore, in a system of Hare voting, this form of protest vote would no longer run the perverse risk of throwing the election in favor of the more conservative candidate, Bush, by preventing potential majority support for Gore as the 
mainstream liberal candidate.

Perhaps the largest difficulty with this method is the amount of information voters are called upon to acquire and process when voting. In a field with relatively few candidates, this might not be terribly difficult, but with multilevel democracy and several choices in each election, the cost of acquiring information can be costly and the process risks reducing voter turnout or increasing voter frustration. Notice that in Australia, which uses a version of this regime, voting is compulsory. (Electoral Backgrounder No. 17 2007; Richie 2004, p. 502).

In general, this voting scheme, including its variations, is likely to work best when voters share substantial common information (for example voters registered to a single party or with relatively few electoral candidates). It remains to be seen whether any concrete applications within the United States will be developed.

Copeland voting (or round robin): Each candidate gets a "Copeland score" based upon win loss ratios and the candidates are then ranked so that a single candidate with the highest score (or multiple candidates) can be selected. (Saari \& Merlin 1996, pp. 1-3). By requiring all potential binary comparisons, this regime meets the Condorcet criterion thus ensuring that available Condorcet winners prevail, but it accomplishes this objective with a considerable administrative cost. As a result, this regime has limited applications. This is also referred to as round robin voting, a regime that is employed in some sports tournaments that facilitate all paired competitions and produce a record of win loss scores. When used in electoral settings, voters are called upon to identify win loss results for all possible paired comparisons among candidates. $^{22}$

The preceding discussion provided an overview of several systems in operation in addition to several proposed voting systems. This background will be helpful in surveying the 
legal literature relying upon social choice to advocate various methods of procedural reform in legislative or judicial processes. In part IV, I will introduce an alternative framework that relies upon social choice, which helps in formulating a response to these proposals and others.

III. Implications for institutional reform

While the prior theoretical discussion suggested several positive insights growing out of social choice, much social choice scholarship, including legal scholarship relying upon social choice, has relied upon the difficulties exposed by such concepts as cycling, agenda setting, path dependence and more broadly Arrow's Theorem to advocate proposals for institutional reform. While it is not possible here to summarize that vast scholarship, let alone provide a comprehensive response to these wide ranging proposals, it will be helpful to provide a sense of the uses to which these theoretical concepts have been put in advancing various normative proposals. The part that follows will address some of these proposals, but more importantly will suggest a framework for considering how to assess social choice based proposals for institutional reform more generally, which can be adapted to various contexts. ${ }^{23}$

One group of legal scholars has questioned whether the phenomenon of cycling undermines the presumption of normative validity respecting legislative outcomes. (Eskridge 1988, pp. 285-89; Stout 1989, p. 1795 n.37; Macey 1986, p. 230-33; Hovenkamp 1990, pp. 9193; Easterbrook 1982, pp. 811-31). Based on the claimed defects that social choice reveals for legislative decision making, prominent legal scholars have challenged legal doctrines that express deference to legislative policy making. Such scholars as William Eskridge, Lynn Stout and Jonathan Macey have challenged the assumption underlying rational basis scrutiny that, absent an identified constitutional violation, federal courts ought to assume that legislatures have rationally processed the preferences of their members and constituents. (Eskridge 1988, p. 279; 
Stout 1989, p. 1823; Macey 1986, pp. 261-66). Instead, based upon social choice insights demonstrating the difficulties with collective preference aggregation, these scholars have argued that judges should engage in more liberal construction of statutes and broader constitutional judicial review to further their (divergent) views of how institutions promote the public good.

Other scholars, most notably Daniel Farber and Philip Frickey, have cautioned against using social choice as a means of enhancing judicial power, claiming instead that to the extent that social choice calls legislative decision making into question, the methodology supports institutional reform within Congress itself. (Farber \& Frickey 1991, pp. 116-18; Farber \& Frickey 1988, pp. 429-30). These scholars maintain that social choice analysis, along with public choice generally, belies purely pluralist conceptions of legislation. As a result of legislative features that have developed in part as a response to potential cycling, they posit that unbridled pluralism is conducive to zero sum pluralist politicking, the modern day equivalent to Madison's factional violence. (Madison 1987, pp. 122-27). These scholars further contend that social choice theory proves consistent with their preferred small "r" republican vision of politics, which favors broad electoral participation and deliberation.

Another group of scholars has relied upon social choice to call into question the processes through which appellate courts, including especially the Supreme Court, resolve cases before them. Based upon a series of cases that appear to ground case outcomes in voting paths, or to otherwise thwart majoritarian preferences, some scholars have suggested changing the Supreme Court's decision making rules so that voting on issues within cases, rather than voting directly on the judgment, should control case outcomes, at least in the unusual cases in which these results diverge. (Kornhauser \& Sager 1986, p. 30; Post \& Salop 1996, pp. 1077-84; Nash 2003, pp. 9395; Meyerson 2005, pp. 946-51). Others have called into question the comparative merit of the 
narrowest grounds rule versus plurality rule in construing non-majority Supreme Court cases. (Levmore 2002, pp. 95-100; Stearns 2002, pp. 135-42).

Finally, in response to some of the more recent difficulties confronting electoral politics in the United States, some scholars have suggested various alternative voting protocols, including most notably variations on Hare, or single transferable, voting. (Richie 2004, pp. 50612). Each of these proposals, and many other proposals grounded in social choice for institutional reform, is based upon the understanding that because Arrow's Theorem proves voting an inherently problematic mechanism for aggregating collective preferences, modifying voting procedures might better promote desired results. Such proposals include placing greater emphasis on intensely held minority preferences or otherwise ensuring more meaningful minority representation.

Whether focusing upon judicial or legislative reform, these scholars are part of a neorepublican scholarly tradition within the legal academy concerned with ensuring that institutions properly represent broad constituencies and protect their preferences against the often hardboiled realities of American politics. (Farber \& Frickey 1991, pp. 12-13). Evaluating these and other such proposals for institutional reform requires a careful comparative analysis of the affected institutions.

Arrow's Theorem proves helpful in undertaking such analysis in a manner that avoids the pervasive “nirvana fallacy.” (Coase 1981, p. 187; Demsetz 1969, p. 1; Stearns 1994, pp. 1229_ 30). Through the nirvana fallacy, scholars identify a defect in a given institution and then, based upon the perceived defect, propose fixing the problem by shifting decisional responsibility somewhere else. The fallacy is in failing to consider whether the alternative institution for which decisional authority is proposed would be better or worse than the originating institution at 
performing the assigned task.

Before setting out a more detailed description of Arrow's Theorem, it will be helpful to discuss two related analytical fallacies. Some commentators have observed that because appellate courts generally, and the Supreme Court in particular, are collective decision making bodies, to the extent that social choice reveals potential defects in the legislative process, so too it reveals defects in the judicial process. (Easterbrook 1982, pp. 818-31; Elhauge 1991, pp. 10108; Elhauge 2008, p. 274-75). Responding to such arguments, Farber and Frickey have suggested that if social choice applies to both legislatures and the judiciary, then social choice is not a particularly helpful tool of analysis. They explain:

In a sense, the ... thesis [that cycling plagues both courts and legislatures] proves too much. If chaos and incoherence are the inevitable outcomes of majority voting, then appellate courts (which invariably have multiple members and majority voting rules) and even the 1787 Constitutional Convention are equally bankrupt. As a result the ... thesis is bereft of any implications for public law, since it tells us to be equally suspicious of all sources of law. If we accept the thesis as to legislatures, we are left with nowhere to turn.

(Farber \& Frickey 1991, p. 55).

Exposing these three identified fallacies helps to provide a stronger social choice analysis of several existing institutional functions and norms. Indeed, this analytical framework provides a strong normative foundation for some of the more enigmatic features of constitutional lawmaking. In the next part, we consider two additional fallacies that help to explore the power of social choice in assessing the relative competence of various institutions at performing various 
lawmaking tasks. Simply put, the analysis to follow reveals that many social choice based criticisms of lawmaking institutions assume the need for a degree of competence at the level of a given institution that Arrow's Theorem proves impossible, but that might be meaningfully accomplished across multiple institutions working in combination. (Stearns 1994, pp. 1257-86). As the discussion in the next part reveals, combining institutional lawmaking processes improves the overall fairness and rationality of outputs even when at the level of a specific institution one can identify a substantial defect characterized in terms of fairness or rationality.

IV. Institutions reconsidered: the composition fallacy, the isolation fallacy and the problem of timing

To illustrate the fallacy of composition, we introduce two hypotheticals. The first is inspired by William Shakespeare, The Tragedy of King Lear, ${ }^{24}$ and the second is based upon a 1992 Supreme Court case, New York v. United States, 505 U.S. 144 (1992). The analysis is designed to demonstrate that collective decision making bodies can improve the quality of their outputs when they operate together and that this holds true even if each institution is separately prone to the problem of cycling.

\section{A. The fallacy of composition}

The fallacy of composition is the assumption that if phenomenon $\mathrm{X}$ produces result $\mathrm{Y}$, more of phenomenon $\mathrm{X}$ will produce more of result $\mathrm{Y}$. For a simple illustration, imagine a proposed housing development in which the basic model house is brick. An individual purchaser could make her home appear distinctive by instead selecting a stone façade. But now imagine that every purchaser shares this intuition and thus seeks to render his or her home distinctive in the same manner. After several home buyers make this decision, it is no longer the case that a stone facade renders a home distinctive. Indeed, if so many purchasers followed this strategy that 
most homes have a stone façade, a home buyer can then render her home distinctive by instead opting for brick. Of course, the same problem would arise if everyone mimicked that strategy.

Similarly, an individual homeowner could make her house safer against burglary by installing an alarm. While sophisticated burglars can get past most alarms, holding all else constant, ${ }^{25}$ alarms divert would be burglars in favor of homes that, lacking alarms, can be broken into with less effort and at lower risk. Of course, if most or all homeowners in the housing complex install an alarm, the diversionary benefit is reduced or eliminated. While it remains true that each alarmed home is slightly more difficult to burgle, the larger benefit of encouraging would-be burglars to thieve elsewhere is substantially reduced. In both examples, phenomenon X (a stone facade or a house alarm) produced result Y (distinction or a reduced risk of burglary relative to neighboring homes) only if a relatively small number of actors followed the distinguishing strategy. Otherwise, if most or all homeowners followed the identified strategy, the benefits of distinction are substantially reduced and perhaps eliminated.

B. Implications for collective choice

We now return to the context that motivated our discussion, namely the problem of cycling in collective decision making institutions. Farber and Frickey aptly expressed the concern: If the problems revealed in Arrow's theorem are a universal feature of collective decision making bodies, then the theory of social choice leaves us 'nowhere to turn.' (Farber \& Frickey 1991, p. 55). After all, while each institution is susceptible of cycling, the theorem might imply that no institution is capable of the much needed rescue.

In fact, however, the fallacy of composition reveals how two collective decision making bodies that each sometimes cycle can reduce cycling by operating together provided that they do not cycle in response to the same underlying phenomena. If each cycles in response to different 
triggers, then it is possible that although phenomenon $\mathrm{X}$ (an institution processing collective preferences) produces result $\mathrm{Y}$ (producing occasional cycling), more of phenomena $\mathrm{X}$ (multiple institutions processing collective preferences) can avoid or reduce result Y (inhibiting cycling).

Within the United States Constitution, for example, Congress and the Supreme Court might improve the overall fairness and rationality of lawmaking, as those terms are used in social choice, through their combined operation. More generally, courts and legislatures might have this effect if the trigger to cycling for each institution is notably different. The most important difference in the nature of the triggers to cycling turns out to be relative timing. Institutions are more likely to cycle when faced with the prospect of allocating the benefits of an unanticipated windfall or gain or the burdens of an unanticipated, or capital, loss. Conversely, institutions are less likely to cycle when issuing outcomes that apply generally and prospectively, and thus before the circumstances capable of generating such a windfall or loss arise. ${ }^{26}$

This part offers two illustrations. The first demonstrates the complementarity between private markets and the legislature and the second illustrates the complementarity between the legislature and courts. The examples themselves are also complementary in that together they demonstrate that the susceptibility to cycling, or the ability to avoid it, is not specific to institutions. In the first example, private actors cycle and the legislature has the capacity to break the cycle. In the second, the legislature cycles and a court has the capacity to break the cycle. These illustrations will demonstrate that there is nothing inherent about the legislature that causes, or elsewhere that avoids, cycling. Rather, any multimember institution can cycle on its own or limit cycling. The particular result in each instance depends upon the nature of each institution's interaction with the factual predicates that motivate (or inhibit) cycling.

C. The problem of the empty core among private actors 
The next two examples rely upon a parallel game theoretical concept to cycling known as the empty core. The first hypothetical will take as its inspiration, William Shakespeare, The Tragedy of King Lear. (Shakespeare 2005). ${ }^{27}$ This version of the story involves a modern yet similarly dysfunctional family. Professor Lear, an eccentric mathematics professor, who has recently won thirty million dollars in the lottery, has long been estranged from his three daughters who are also estranged from each other. Because the daughters have not had any contact with Lear for over ten years, when their mother died, they are unaware that he won the lottery five years earlier. To simplify the presentation, assume that the full lottery proceeds were distributed as a single lump sum with no discounting. Upon winning the lottery, Lear did not change his reclusive lifestyle. Instead, he placed the full proceeds of the lottery into a trust fund, with the objective of passing the money to his daughters if certain conditions were met. Five years after winning, Lear was diagnosed with a fatal disease and told that he had only six months to live. After he was informed of his diagnosis, Lear saw an opportunity to construct a controlled high stakes social choice experiment with real players.

Lear immediately contacted the administrator of the trust and had the trust's terms modified as follows. If the terms governing the distribution of the corpus of Lear's trust for the lottery winnings were satisfied by the time of his death, the full proceeds of the trust would then be distributed in accordance with his daughters' assented to division of the trust assets. Failing that, the corpus of the trust would instead pass into the residuum of Lear's will, from which it would be used to endow the new Lear Institute, a research center devoted to studying applied social choice and game theory.

The relevant provisions of the trust require that the full proceeds are to be distributed according to a plan submitted by the daughters, provided that two conditions are met. The first is 
that the allocations must be agreed upon by two of the three daughters by no later than 5:00 p.m. 10 consecutive days prior to Lear's death. The last plan that meets this 10 day rule without being superseded by another plan will be regarded as final. Second, after the final plan is submitted, any daughter, whether or not a signer of the final distribution plan, will forfeit her entire share in the event that she seeks to alter the agreed to distribution by any means other than forming a superseding coalition. This includes filing an action in a court of law or equity. In the event that this should occur, her share will be forfeited and divided equally between the remaining sisters provided their agreement otherwise satisfies the terms of the trust. The trust further provides that the daughters can employ any rules that they wish to achieve a distribution, provided it is accomplished privately and without violating any criminal laws. The sisters cannot rely upon any court of law or equity to develop or to enforce any agreements. Upon being in receipt of the basis for final distribution for 10 consecutive days prior to Lear's death without the plan being superseded by a later filed plan, the trust administrator is to immediately notify Lear of the terms of the final distribution. Otherwise, the full corpus of the trust shall pass to the residuum of Lear's will.

Before considering how the daughters might respond, a few general comments about the hypothetical will be helpful. Under the terms of the trust, the daughters are expected to agree to an outcome governing the distribution of what will be an extremely valuable windfall. Of course one daughter can try to supersede any proposed solution with an alternative provided that she forms a new coalition and files in time to meet the 10 day requirement before Lear's death. In addition, while the daughters are permitted to employ any background rules they wish, they will suffer a complete forfeiture if they try to have those rules legally enforced. Under the terms of the trust, a minimum of two out of the three daughters must agree upon, and submit in writing, 
the terms of the final distribution for the requisite 10 day period. Thus, no individual daughter can disrupt this plan unless she forms a superior coalition that files a superseding plan subject to the same rule. Finally, while the daughters are aware that Lear is terminally ill, no one knows precisely when he will die and thus each later filed plan increases the risk that his death will fail to meet the necessary 10 day filing period to satisfy the terms of the trust.

Now consider the options confronting the daughters. One obvious solution exists: Each daughter could take $\$ 10$ million and the three now wealthier sisters could go on with their lives. Based upon this intuition, Daniel A. Farber and Philip B. Frickey have posited that in such cycling games, simple and obvious fairness (or value) solutions like equal division provide practical and potentially stable solutions. (Farber \& Frickey 1988, p. 434). Farber and Frickey posit that the desire to avoid 'setting off a round of endless cycling' provides a 'new form of equilibrium adopted precisely to avoid the cycles.' (Farber \& Frickey 1988, P. 434).

Before evaluating whether the value solution proves a stable outcome, consider the pathology that underlies our hypothetical. This hypothetical is a classic illustration of an empty core bargaining game. As with all such games, the difficulty confronting the players is that for any existing coalition, there exists an alternative superior coalition that can improve the payoffs for an excluded party and a defector. (Wiley 1987, p. 558; Stearns 1994, pp. 1233-40). Because this holds true for any potential coalition, no coalition is stable. In contrast, a game has a core, thus producing a stable solution, when, for a coalition or set of coalitions, there is no alternative superior coalition that will improve the plight of an excluded party and a defector. Because this game has an empty core, for any proposed solution there exists an alternative favored by a newly formed coalition, thus generating a cycle.

To simplify, assume a pool of $\$ 30$, where each dollar represents $\$ 1$ million. Further 
assume that Goneril and Regan begin by submitting a plan for each to take $\$ 15$ each. Cordelia can now break up that coalition within the allotted 10 day period by offering Regan $\$ 20$ and agreeing to take only $\$ 10$. Goneril, the excluded party, can now break up the new (Cordelia, Regan) coalition within the 10 day period by offering Cordelia $\$ 20$, and herself taking $\$ 10$. And now Regan, the excluded party, can break up the (Goneril, Cordelia) coalition within 10 days by offering Goneril \$20 and herself taking $\$ 10$. Of course, now Cordelia, the excluded party, can start the ball rolling again, thus breaking up the second (Goneril, Regan) coalition, this time by offering Regan \$20 and agreeing to take only \$10. The coalitions have now come full circle, with (Goneril, Regan), split 15/15, replaced by (Regan, Cordelia), split 20/10, replaced by (Cordelia, Goneril), split 20/10, replaced by (Goneril, Regan), split 20/10. And yet, the final listed coalition is no more stable than it was in the initial round. It might appear that the whole problem would be solved if, as previously suggested, the three sisters simply agreed to submit a written plan calling for equal division. But little effort is required to show that this merely restores the empty core game. $^{28}$

We can only speculate, of course, what the final outcome would be and whether the daughters would reach a satisfactory resolution lasting 10 days without a later filing before their father's death or whether as a result of efforts by the excluded sister to improve her payoff by forming a new coalition the daughters would ultimately force the trust corpus into the residuum of their father's will and take nothing. It is also important to observe that even if they succeeded in forming a successful coalition that met the requirements under Lear's will, say the equal division value solution that Farber and Frickey propose, that result would necessarily embed a thwarted majority that would have received higher payoffs had they instead supplanted that result in favor of a superior alternative coalition. 
Whatever the actual outcome, it is sufficient to note the risk that cycling will prevent a final timely disposition of assets or will embed an outcome disfavored by an alternative controlling majority. In contrast, in this example, lawmaking institutions appear to have a comparative advantage over private decision makers in avoiding the pitfall of cycling. And yet, as we will see in a later example, under alternative conditions, lawmaking bodies themselves are prone to cycling. As the next variation on the Lear hypothetical demonstrates, the institutional comparative advantage in avoiding the difficulty of cycling is a function of timing. Empty core bargaining problems arise when parties negotiate after the facts producing an unanticipated windfall or capital loss have already arisen.

Let us now modify the hypothetical to allow the sisters to enforce any interim agreements legally without sacrificing any of the resulting gains. In this revised hypothetical, Lear's trust does not prevent the sisters from invoking judicial enforcement of a standard expectancy damages rule for breach of contract. ${ }^{29}$ This rule imposes liability upon the breaching party and restores the victim of the breach to the position she would have been in had the breaching party fully performed. (Calamari \& Perillo 1998, pp. 543-46). While it is not possible to predict which particular coalition might give rise to a breach of contract action, for any coalition that does form, anticipating this basic contract rule restores the stability of the initial result.

To illustrate, assume that Goneril and Regan submit the original plan for each to receive \$15. Cordelia proposes a superior coalition to Regan in which Regan receives $\$ 20$ and Cordelia receives $\$ 10$. With the contract rule now in place, Regan will rationally decline. If Regan enters into this superior coalition, she gains a marginal increase of \$5 (\$20 rather than $\$ 15)$, but risks forfeiting \$15 (the full amount of Goneril's loss) in compensatory damages. Thus entering the superior coalition with the compensatory damages regime in place puts Regan in an inferior 
position relative to maintaining the original bargain. The principle can be generalized. Once any coalition has formed, an expectancy damages rule will ensure that any gains to the defector from forming a superior coalition with the initially excluded daughter will be depleted. ${ }^{30}$

The contract damages rule might appear to avoid any possibility of cycling, but this is an oversimplification. This seeming solution has the potential to simply shift the threat of a cycle back to pre-contractual negotiations. While any coalition that actually formed would be stable with such a rule in place, at the preliminary negotiating stage, the very same empty core problem has the potential to rear its ugly head. Preliminary coalitions can, in theory, form and reform prior to any formal agreements that, once breached, would give rise to a contract damages action.

The expectancy damages rule is not the only solution to the problem of cycling in such situations. A legislature can also induce stability among private actors facing an unanticipated windfall or capital loss through a rule taking the form of a property right. Let us now modify the hypothetical and assume that Lear dies intestate. As we have already established, the sisters, left to their own devices, have the potential to cycle over the various alternative allocation schemes. This problem is solved, however, in the laws of virtually every state under which the sisters take in equal shares. (McGovern 2004, 25-36).

To see why the legislature can devise this simple and indeed compelling solution when the sisters seem unable to do so, consider the different incentives that confront the private market actors versus the lawmaking body in this example. While the sisters are motivated by the desire to maximize their individual payout once the windfall is announced, the legislature is instead motivated to announce rules that apply generally and prospectively. If successful, the rule will mirror what the parties would have agreed to prior to the announcement of the windfall gain. And even if it is not, the rule might still enhance social welfare by providing a negotiation point 
for future contracting. But after such a windfall is announced, the sisters no longer find themselves in the same ex ante frame of reference that helps to avoid unattractive strategic behavior. In this game, the legislature is well suited to replicate the more beneficial ex ante perspective on the sisters' behalf and for that reason can develop a solution that limits cycling when operating in combination with the sisters acting privately.

Consider once again the suggestion that because all institutions are theoretically prone to cycling, social choice leaves us 'nowhere to turn.' (Farber \& Frickey 1991, p. 55). The answer may lie in the fallacy of composition. Provided that the separate institutions prone to cyclingprivate actors seeking to allocate a large windfall gain and the legislature seeking to devise an $e x$ ante off the rack rule-cycle in response to different factual phenomena, they can reduce the risk of cycling, and perhaps avoid it altogether, by operating together. ${ }^{31}$

As the next hypothetical demonstrates, legislatures can also be victimized by cycling when the legislators themselves are victims of an unanticipated capital loss (or the beneficiaries of an unanticipated capital gain). When this occurs, legislatures might benefit from a judicial response.

D. Location of toxic waste disposal facility

The next hypothetical is based upon the 1992 Supreme Court decision, New York v. United States, 505 U.S. 144 (1992). This example illustrates the conditions under which a state legislature, which in the prior illustration was able to devise a stable solution to an empty core bargaining game among private actors, can itself fall prey to the problem of empty core bargaining or cycling. The New York Court struck down the take title provisions of the Low Level Radioactive Waste Policy Amendments of 1985. These amendments were enacted after a series of unsuccessful regulatory initiatives designed to ensure adequate facilities for storing low 
level radioactive waste. The amendment solved this problem by imposing sufficient sanctions such that the individual states would be motivated either to become self sufficient or to join in a pact with other states that collectively would be self sufficient.

Under the terms of the Amendments, states that failed within a specified time frame to join a successful regional waste disposal pact with other states or to become self sufficient by creating their own in state waste disposal facility were required to take title to low level radioactive waste or to compensate producers for any resulting liability. While the Amendments produced a series of three compliance incentives that were intended to ensure self sufficiency on the part of states by the end of 1992, Justice O’Connor, writing for the New York Court, determined that only the take title provisions exceeded Congress's powers under the commerce clause, or alternatively, under the 10th Amendment.

The case facts revealed that by 31 December 1992, the compliance deadline under the 1985 Amendments, only New York had failed to either join a regional pact or to create an in state disposal facility for low level radioactive waste. New York then filed suit to challenge the take title provisions as exceeding the permissible scope of Congress's regulatory powers under the Commerce Clause. The facts further revealed that, while New York had initially decided to join a regional pact, it later opted instead to create an in state disposal facility. The New York State Assembly eventually rejected each of five proposed sites, with the result that New York was the only noncompliant state and thus the only state subject to the onerous take title provisions.

Consistent with the preceding analysis, the following stylized rendition of the New York facts demonstrates how the state legislature is prone to cycling following the new federal regulatory requirements. Imagine that instead of five proposed sites there are three, A, B and C. 
Consider the incentives among the legislators representing those districts or for three groups of legislators such that any two form a majority. The general problem of course is that no legislator wants the facility in her own district, a phenomenon that environmentalists refer to as Not In My Back Yard, or simply NIMBY. (Glickman \& Levy 2008, pp. 600-01). Assume that AB form a majority voting to place the facility in C. C can offer A a sufficient legislative perk or promise of some future commitment to form a superior CA coalition, with the result of instead voting to place the facility in B. B can now propose a similar deal to $\mathrm{C}$ if $\mathrm{C}$ defects in favor of a superior BC coalition, voting to place the facility in A. Now A can make a similar promise to B, reforming the now superior $\mathrm{AB}$ coalition, and once again voting to place the facility in $\mathrm{C}$. At this point the coalitions have come full circle-AB, BC, $\mathrm{CA}, \mathrm{AB}$ - with the facility voted to be placed in C, B, A, C. Of course no outcome is stable because this game, like the Lear game, has an empty core.

The question then is why the state legislature is itself prone to cycling in this example when in the prior example involving the allocation of assets in the absence of a will, the state legislature succeeded in eliminating the sisters' cycling problem. The answer rests upon appreciating how different decision making bodies are affected by the timing of the factual predicates that potentially motivate a cycle. When faced with the issue of how to allocate the proceeds of a large and unanticipated windfall, the sisters were not concerned with devising the best or most equitable public policy respecting the division of assets among siblings in the absence of a will. Instead, each sister was concerned with engaging in whatever strategy maximized her personal gain. In the absence of a core, these combined strategies produced a cycle. In contrast, the legislators, when developing a prospective regime governing rules of heredity in the absence of a will, sought to devise a fair and general solution. That is a 
characteristic feature of off the rack rules, whether taking the form of contractual rules (the expectancy damages rule) or property rights (the equal division rule). While the legislators were therefore able to devise an ex ante solution to this bargaining problem, the sisters were instead motivated by the desire for ex post gain. The legislators, unlike the sisters, were able to behave as if the relevant facts giving rise to a potential cycle had not yet occurred. Even though legislators are prone to cycling when they are confronted with a capital loss (allocating the burdens of a newly imposed regulation that requires locating a waste facility), they are able to inhibit cycling among private actors when constructing a general and prospective off the rack rule. This beneficial result obtains even though both private market actors and legislators are sometimes prone to the problem of cycling.

E. On the significance of logrolling and structure induced equilibria While the prior discussion identifies circumstances that limit legislative cycling, the question remains how general the problem of legislative cycling actually is. In a famous essay entitled "Why So Much Stability?," Gordon Tullock questioned the practical significance of cycling in the face of generally stable institutional outcomes. (Tullock 1981, pp. 194, 200). Tullock observed that despite the pervasive literature on legislative cycling, documented illustrations of cycling are rare or nonexistent. Tullock proposed that the apparent gulf between theoretical scholarship and empirical observation on this issue results from logrolling or vote trading. ${ }^{32}$ Tullock maintained that this common practice induces legislative stability by allowing legislators to express cardinal values rather than mere ordinal rankings over options. As we have seen, several voting procedures provide proxies for cardinal values as a means to avoid cycling. Tullock posited that the process of vote trading accomplished this function in legislatures.

In a series of articles, Kenneth A. Shepsle and Barry Weingast questioned Tullock's 
explanation, demonstrating that when participants lack different intensities of preference, logrolling itself conduces to cycling. (Shepsle \& Weingast 1981, pp. 503-17; Shepsle \& Weingast 1987, pp. 85-103; Mueller 2003, pp. 106-08). Schepsle and Weingast suggested a more general response. They suggested that a variety of institutional structures in Congressincluding committees, calendaring rules, the filibuster and bicameralism-induce stability by raising the cost of identifying and commodifying potential cyclical preferences. In effect, these and similar procedural devices create gateways for decision making that limit the ability of participating legislators to discover or register preferences over options. Without this information, legislators lack the means with which to challenge outcomes selected at various lawmaking junctures as thwarting majoritarian preferences.

Social choice thus helps to offer a positive account for the emergence of lawmaking structures that serve as venues for interest group participation in legislative processes and that, as such, are often the focus of interest group theory. Not surprisingly, these structures raise questions of their own concerning the normative merit of legislative outcomes.

In response to an argument by Farber and Frickey concerning the relevance of cycling for legislatures, Shepsle addressed this question. Farber and Frickey, responding to the apparent paradox of stable legislative outcomes despite the large literature on cycling, state: ‘Arrow’s Paradox is both fascinating and illuminating, but it may have little direct relevance to legislative practice.' (Farber \& Frickey 1987, p. 904). Now consider Professor Sheplse’s response:

The authors are confused by the fact that even in voting processes victimized by the Arrow result, we are sometimes able to identify equilibria. These equilibria, however, are strongly affected by the underlying incoherence of majority preferences and, because of this, lack a compelling normative justification. 
Arrow's theorem does not necessarily entail constant flux and indeterminacy; rather, it implies that the manner in which majority cycling is resolved is arbitrary or otherwise morally indefensible.

(Shepsle 1992, p. 242 n.6).

While Shepsle is certainly correct that by raising the cost of disclosing potentially cyclical preferences these institutional structures have the potential to produce equilibrium outcomes, the important normative question is whether, consistent with Shepsle, we should regard the resulting outcomes as 'arbitrary or otherwise morally indefensible.' In Shepsle's analysis, the admittedly stable outcomes lack normative justification inasmuch as they thwart majority preferences for an alternative, and suppressed, outcome. This is an important posit because it calls into question the moral foundations of a system of law grounded in legislative policymaking that will often result from arcane lawmaking procedures.

To evaluate this claim, it is important to distinguish what Shepsle labels the normative justification for such outcomes from what we will instead label the normative legitimacy of such outcomes. (Stearns [2000] 2002, pp. 63-64). Legitimacy goes to societal acceptance of outcomes based upon the quality and acceptance of the processes that generated them. ${ }^{33}$ Society might agree upon procedures that facilitate results even when preferences sometimes cycle thus rendering selected outcomes legitimate even if on occasion society laments particular outcomes as arbitrary and thus lacking justification as indicated by a merits based comparison with foregone alternatives.

Shepsle suggests that because structure induced equilibrating rules conduce to seemingly arbitrary outcomes, at least when compared with foregone alternatives that other majorities 
would have preferred, actual outcomes should be regarded as normatively suspect. William H. Riker has made a similar argument about particular Congressional outcomes (Riker 1982, pp. 152-56), and Judge Frank Easterbrook has done so with respect to the outcomes of Supreme Court cases influenced by structure induced path dependence. (Easterbrook 1982, pp. 817-21). It is on the basis of such insights that Farber and Frickey maintain that social choice theory 'proves too much' since its broad application to all lawmaking bodies including legislatures and appellate courts leaves us with 'nowhere to turn.' (Farber \& Frickey 1991, p. 55). While the preceding analysis of the combined operation of institutions that cycle on their own explains why social choice does not leave us at such an impasse, the distinction between legitimacy and justification responds to the concerns raised by Shepsle, Riker and Easterbrook concerning the normative merits of particular outcomes that follow from structure induced equilibrating rules.

To summarize, the pervasiveness of theoretical cycling among all collective decision making bodies does not imply that social choice undermines institutional competence across the board. Rather, it suggests the need to consider the differences between or among institutions and how institutions operate in combination to ameliorate each other's deficiencies. In addition, within institutions, procedures that raise the cost of identifying preferred alternatives to a proposed outcome can also inhibit cycling. While structure induced equilibrating rules might render outcomes path dependent (with the result that other potential outcomes are preferred by thwarted majorities), societal acceptance of the fairness of processes generating such outcomes might nonetheless legitimate the resulting outcomes.

F. A preliminary comparison between legislatures and appellate courts

Even with structure induced equilibrating rules in place, with sufficiently high stakes, legislators are sometimes able to identify intransitivities through informal means. This does not 
mean that legislators necessarily identify cycles as such. Instead, given large stakes, legislators will discover information from which they can infer that a majority prefers an alternative to a proposed or selected outcome. ${ }^{34}$ When this occurs, legislators might intuit the absence of a normative justification for moving forward with a proposed bill that would change the legal landscape but that appears to lack adequate political support.

In contrast with this combination of formal and informal mechanisms that allow legislative bodies to discover and to decline to act when faced with intransitive preferences, appellate courts generally carry an institutional obligation to issue a collective decision regardless of whether a Condorcet winning option exists. When judicial preferences are prone to cycling in a given case or over a group of cases the Supreme Court nonetheless remains obligated to resolve the cases even though in doing so it will inevitably thwart the preferences of a majority of its members in some respect. (Stearns [2000] 2002, pp. 164-65).

Unlike appellate courts, legislatures possess one other important means of avoiding the difficulties that cyclical preferences sometimes pose. While appeals court judges are generally understood to vote in a principled manner on case outcomes and on issues that particular cases present, ${ }^{35}$ legislators routinely vote trade both within and across bills. As Shepsle and Weingast have observed, with uniform intensities of preference, vote trading itself can produce cycling. (Shepsle \& Weingast 1981, pp. 503-17). Of course preference intensities are not typically uniform and as a result vote trading produces opportunities for exchange that improve payoffs as compared with simple majority preferences.

To illustrate, consider the following hypothetical illustration of a welfare inhibiting legislative outcome offered by William Eskridge:

Assume that Legislator A controls the agenda, so that Decision 1 is the last to pair 
up, winning against Decision 3. In addition, assume that the social benefit of Decision 1 is 100 (55\% of which accrues to District $A$ and $45 \%$ to District $B$ ) and that the social benefit of Decision 3 is 120 (shared equally by the three Districts). Obviously, from the collective point of view, the best decision is Decision $3 \ldots$, yet a coalition of $A$ and $B$ will vote for Decision 1 . This is not only unfair to $C$ (which gets no benefit even though it pays taxes), but is collectively wasteful as well (to the tune of 20).

(Eskridge 1988, p. 284). In this illustration, Eskridge assumes that the legislators vote solely in accordance with their immediate ordinal assessments over options with the result of a social welfare loss of 20 operating entirely to C's detriment. And yet, if these legislators anticipate future interactions, this seems an unlikely result. Instead, legislators A and B would recognize the potential for gains from trade. If A is willing to forgo a payoff of 15 (55 from Decision 1 minus 40 from Decision 3) and if B is willing to forego a payoff of 5 (45 minus 40), thus foregoing combined benefits of 20, the entire group, ABC, gains an additional payoff of 20 . This obviously constitutes a substantial welfare enhancement. In this case, C receives the immediate benefit, increasing the payoff from 0 to 40 (15 from A, 5 from B, plus the entire social welfare gain of 20). Provided that $\mathrm{C}$ is willing to promise a future payoff to A and $\mathrm{B}$ in an amount between the 20 they redistributed to $C$ and the total benefit to $C$ of 40 , the far more likely result in this example is Decision 3, which yields no social welfare loss. This preferred result arises because vote trading allows the members to set cardinal utilities over options.

The same intuition explains how vote trading can avoid a cycle. ${ }^{36}$ While ordinally ranked preferences can yield cyclical outcomes in a regime of unlimited majority rule over binary 
comparisons, in many instances theoretical cycles prove inconsequential. Assume that three legislators possess cyclical preferences (1: ABC; 2: BCA; and 3: $\mathrm{CAB}$ ) and that following a regime of path induced voting, the likely result, benefitting legislators 2 and 3, is C. Despite these ordinal rankings, legislator 1, who winds up with her last choice, might care more intensely about this issue than either legislators 2 or 3 . If so, legislator 2 or 3 might be willing to support an alternative outcome favoring legislator 1 in exchange for legislator 1's future reciprocal accommodation on some other matter. Thus, because logrolling is most likely when participants hold different intensities of preference, as Gordon Tullock has posited, vote trading has the potential to avoid many theoretical cycles. (Tullock 1981, pp. 194, 200).

Sometimes thwarting available Condorcet winners produces a higher degree of social welfare than finding one and logrolling facilitates this result. This follows from the limitation that the Condorcet criterion, along with majority rule more generally, does not account for intensities of preference. Imagine that the legislators hold the following preferences, yielding B as the Condorcet winner: 1: ABC; 2: BCA; 3: CBA. While legislator 1 ranks option $\mathrm{B}$ second, it is possible that she significantly prefers option A while legislators 2 and 3 do not care very much about this particular legislative issue. If so, legislators 2 and 3 might be willing to subordinate their ordinal ranking over these options to produce a more beneficial result for legislator 1 in exchange for a reciprocal future commitment.

Now compare private market exchange. As shown in the Lear hypothetical, private actors can also cycle over options. This is most apt to occur when markets are thin, meaning insufficiently robust to allow competitive forces to attach meaningful cardinal values through the pricing mechanism. In thick markets, in contrast, a robust pricing system facilitates meaningful commodification of preferences, thus restoring cardinal values. ${ }^{37}$ The result, once again, is to 
render many theoretical cycles inconsequential.

While the various voting mechanisms described above have the potential to thwart majority preferences, that insight is only a starting point for assessing the merits of a procedural rule. A careful social choice analysis must go beyond considering dissatisfaction provoked by particular institutional outcomes and must also consider more broadly whether the institution under review functions better overall with or without the rule that generated that result. In addition, social choice requires comparative institutional analysis that identifies each institution's Arrovian deficiency based upon its combined internal rules and structures.

G. A comment on baselines

As the preceding analysis demonstrates, social choice reveals several normative dimensions for assessing the quality of institutional outputs and the processes that institutions employ to generate those outputs. While these baselines grow out of economic analysis generally, they extend well beyond the traditional concern for promoting microeconomic efficiency. The prior discussion exposes no fewer than the following five baselines:

1. The Condorcet criterion,

2. Ensuring collective outcomes whether or not preferences cycle,

3. Controlling or limiting agenda manipulation,

4. Encouraging principled rather than strategic decision making, and

5. Allowing commodification of preferences when individuals hold different intensities of interest in particular outcomes.

Broadening economic analysis to include these and perhaps other baselines promotes a substantially richer analysis than applying any single baseline. What is missing is a framework for assessing the tradeoffs that these or other normative baselines impose in the design of 
collective decision making institutions.

In effect, the analysis thus far was directed at understanding potential institutional objectives: What goals do we as a society hold for the institution under review? The next part, which provides a more detailed introduction to Arrow's Theorem, is instead directed at the question of institutional capacities: What does social choice tell us about the ability of institutions to satisfy society's objectives and at what cost in terms of core democratic values or institutional rationality?

\section{Arrow's Theorem revisited ${ }^{38}$}

Arrow's Theorem proves that all institutions contain some inherent weakness or set of weaknesses at least as compared with what Arrow defined as a minimally acceptable set of benchmarks in assessing institutional competence. Whether the identified weaknesses of any given institution are the basis for serious concern or simply the price of doing business turns in large part on the specific functions we expect our institutions to perform. As you read the discussion that follows, consider how Arrow's various normative criteria help to inform our understanding of the quality of institutions as well as the choice among institutions for various functions in a constitutional democracy.

\section{A. A closer look}

Kenneth Arrow set out to create a set of governing rules to be used by a planning authority that would simultaneously satisfy a fundamental tenet of rationality, namely the ability to ensure that the authority's collective decisions satisfy the minimal criterion of transitivity, and several seemingly noncontroversial assumptions about fair collective decision making processes. ${ }^{39}$ Although then unaware of the work of the Marquis de Condorcet, Arrow ultimately demonstrated that any effort to fix the problem of collective indeterminacy or irrationality that 
results from the problem of cycling will necessarily violate at least one important condition commonly associated with fair collective decision making. Arrow’s Theorem has therefore aptly been characterized as a generalization of the Condorcet paradox. (Riker 1982, p. 116). Arrow proved that no collective decision making body can simultaneously satisfy four seemingly uncontroversial assumptions about fair collective decision making and guarantee the ability to produce collective results that satisfy the basic condition of transitivity. Thus, while Condorcet demonstrated that the general assumption of individual rationality cannot be extended to groups, Arrow demonstrated that devices designed to cure collective irrationality will undermine collective fairness in some fundamental way.

Before explaining the four conditions that Arrow presumed essential to fair collective decision making, a few comments on methodology will be helpful. While the term 'fairness' is admittedly general, Arrow defined each fairness condition with mathematical precision in his axiomatic proof and defended each condition on credible normative grounds. That is not to suggest that every fairness condition is equally important or that all fairness conditions have been universally accepted for their normative validity, at least in all contexts. For now it is sufficient to note that individually and collectively the various fairness conditions are sometimes at odds with both traditional economic understandings of efficiency and rationality, where rationality is defined to mean ensuring the power to translate internally consistent member preferences into transitive orderings for the group as a whole.

In an important respect, the whole of Arrow's Theorem is greater than the sum of its parts. Even if we were to flatly reject either the normative validity of Arrow's understanding of collective rationality or one or more of his claimed fairness conditions, ${ }^{40}$ this would not undermine the power of the theorem as a positive tool in establishing benchmarks for a 
meaningful comparison of institutions and rules. That seeming counter intuition is closely linked to the nirvana fallacy. The nirvana fallacy occurs when a scholar identifies a defect in a given institution or rule and then proposes either shifting decisional authority elsewhere or devising a different governing rule without having first assessed whether the proposed alternative would improve or exacerbate the problem that it is offered to cure. This intuition was most notably expressed in Voltaire’s observation that '[t]he perfect is the enemy of the good.' (Golub 2008, p. 134). Surprisingly, perhaps, in undertaking comparative institutional analysis it is more difficult to ascertain what is good than it is to define what is perfect. Of course Arrow never sought to define a perfect institution, but rather an adequate one that honored what he regarded as basic conditions of rationality and fairness. Even so, Arrow proved the impossibility of achieving his seemingly modest objectives. In doing so, Arrow provided an important combined set of normative benchmarks for comparative institutional analysis. Whether or not Arrow's Theorem defines the 'perfect,' what we will now term Arrow's Corollary defines the 'good enough,' or more to the point, the 'good enough for our purposes.' To see why, we will now frame Arrow's Corollary.

Arrow's Theorem proves that no single collective decision making body can simultaneously satisfy four simple conditions of fairness: range (the outcome must be consistent with the members' selection among any conceivable ordering over three options), unanimity (the Pareto criterion, but with a twist), independence of irrelevant alternatives (in choosing among options presented, the decision makers are to decide based solely upon the merits and without regard to how they would rank options that might later be introduced), and nondictatorship (the decision making rule cannot systematically honor the preferences of an individual against the contrary preferences of the group as a whole), while ensuring the ability to transform 
individually rational inputs into transitive (or rational) group outputs. ${ }^{41}$ After describing Arrow's Corollary, this part will provide more detailed definitions of each of these terms and connect the definitions with several of the examples that we have already seen.

We turn now to a necessary corollary to Arrow's Theorem: Because no collective decision making body can ensure compliance with all five stated criteria (the four fairness conditions plus collective rationality), any collective decision making body that functions, meaning simply that it issues collective decisions, has necessarily sacrificed at least one (and possibly more than one) of these five criteria. (Stearns [2000] 2002, p. 83). This corollary implies that not all of the five criteria are essential to the functioning of all institutions. Moreover, conditions that are essential in some institutions are easily sacrificed and might even prove detrimental in others. This argument rests on the following normative posit: As a society, we do not reject all of our collective decision making bodies-including markets, state legislatures and Congress, state and federal appellate courts and agencies—as inherently irrational or unfair. This holds even though we are sometimes dissatisfied with the particular results that these institutions produce. Assuming this is true, then there must be a standard for evaluating our collective decision making institutions which, although rendering them below the unattainable goal that Arrow's Theorem establishes, nonetheless renders them generally acceptable, or good enough.

By prescribing the unattainable, the Arrow's Theorem criteria provide a set of objective standards with which to assess institutions, knowing that each separate institution will necessarily come up short in some respect. As previously noted, however, Arrow's proof says nothing about which of the particular criteria are most (or least) important in any given institutional setting. It is for that reason that Arrow's Theorem speaks to institutional capacity, 
but not institutional objectives, at least once we realize that the theorem itself demands inevitable tradeoffs on Arrow's own terms. If we use Arrow's Theorem as the benchmark in making such comparative institutional assessments, however, we can determine the nature of each institution's different capacities and, most notably, each institution's deficiencies. Based upon identified deficiencies, we can then assess whether the existing allocation of decisional authority is less bad than the alternative allocations that would result from the various proposals for institutional reform. In addition, by applying the same analysis to rules within institutions, we can once again evaluate proposed changes to those rules to see if they are likely to improve or worsen whatever problems in institutional functioning those proposing the change seek to cure.

Comparative institutional analysis implicates the fallacy of composition and the closely related isolation fallacy. One important method of improving institutional fairness and rationality, including for example in Congress and the Supreme Court, is through the combined operation of institutions in a manner that allows each to help compensate for the other's identified deficiencies. Evaluating an institution as if it were operating in isolation undervalues its quality as compared with considering the combined effect of two or more institutions, each of which carries different strengths and weaknesses exposed by a careful social choice analysis. One important example involves the evolution of initial Supreme Court rules away from the Condorcet criterion (for example outcome voting and stare decisis) and the evolution of initial Congressional rules and practices toward the Condorcet criterion (for example motion and amendment voting or informal practices that allow the discovery of thwarted majority preferences).

This is not to suggest that the Supreme Court generally misses available Condorcet winners, ${ }^{42}$ or that Congress invariably finds them. Rather, the starting point for the rules that 
develop in each institution reflect each institution's general obligation to either resolve matters properly before it or its power to remain inert when confronted with proposals lacking sufficient support for collective action. Just as institutions can complement each other, thus improving fairness and rationality, so too can rules within a particular institution. In the Supreme Court, the outcome voting rule, which poses a generally binary choice-affirm or reverse-for the resolution of a case judgment, ensures a collective outcome on the judgment even when the preferences of the justices cycle over the outcome and the underlying rationale. (Stearns [2000] 2002, pp. 86-87). The Court combines the outcome voting rule with the companion narrowest grounds rule, which ensures that if in a non-majority case the Court nonetheless possesses a Condorcet wining opinion, the Court will select it as expressing its holding. Thus these combined rules, outcome voting and the narrowest grounds rule, improve the Court's rationality (ensuring outcomes even when preferences cycle) and fairness (ensuring Condorcet winners when preferences do not cycle).

Congress, in contrast, does not have an institutional obligation to act on all proposed bills. Its rules do not invariably demand formal action, and yet it employs structure induced equilibrating rules that potentially raise the cost of locating intransitive preferences. Even so, through various informal means, members of Congress can locate potentially thwarted majorities when stakes are high and negotiate against adverse voting paths, thus improving the probability of satisfying the Condorcet criterion or the quality of group outputs through commodification of preferences. The analysis reveals that the starting point in the development of institutional rules is substantially informed by the differing institutional responsibilities that arise in the event that member preferences are prone to cycling.

B. A more detailed application 
This part sets out a more comprehensive introduction to the Arrow's Theorem criteria which ties together several of the concepts developed in this chapter and provides a basis for further applications of social choice to specific institutions and rules. In the simplified version of the proof, Arrow's Theorem establishes that no single institution can simultaneously satisfy four conditions of fairness and ensure collectively rationality. (Vickrey 1960, pp. 507-09; Stearns 1994, pp. 1291-92). The discussion below provides a more detailed definition of each of the fairness criteria and links these definitions to the earlier discussion.

Range (and the Condorcet criterion): Range requires that when a group is selecting among three options the outcome be the universal product of a rule that permits all members to rank all three options in any order. (Stearns [2000] 2002, p. 84). This condition, which when honored ensures adherence to the Condorcet criterion, is best explained with an application. For three options $\mathrm{ABC}$, there are six potential sets of ordinal rankings. While we can easily list all six ( $\mathrm{ABC}, \mathrm{ACB}, \mathrm{BAC}, \mathrm{BCA}, \mathrm{CAB}, \mathrm{CBA})$, we can also express this mathematically as three factorial. For the first choice ranking, the decision maker can select among all three options, for the second choice ranking between two options, and for the final selection only one option remains. Three factorial, the product of these three choice sets (3x2x1), equals six.

Range has two components, one governing the participants' freedom of choice over options, the other governing the nature of the rule used to combine these rank orderings into a group outcome. Adhering to range requires that each decision maker be permitted to select from any of those potential six combinations of ordinal rankings so that none is off limits. Range also requires that the decision making rule select an outcome that is consistent with each member's selection from the various sets of ordinal rankings.

When broken down into these constituent parts, the range criterion appears intuitive. If 
participants are not permitted to rank all options in the order of their choosing (thus permitting selection from all combined ordinal rankings over options), then whoever decides which combined rankings are off limits can exert disproportionate power relative to the other participants over the ultimate decision. It is for this reason that adhering to range furthers democratic norms. We have already seen some examples. Recall that in a group with non Condorcet winning preferences ( $\mathrm{ABC}, \mathrm{BCA}, \mathrm{CAB})$, a regime that permits unlimited pairwise voting will disclose a cycle, such that $\mathrm{ApBpCpA.} \mathrm{If} \mathrm{instead} \mathrm{range} \mathrm{is} \mathrm{restricted} \mathrm{so} \mathrm{that} \mathrm{the} \mathrm{ranking}$ $\mathrm{CAB}$ is off limits, then out of the six potential options (ABC, ACB, BAC, BCA, CAB, CBA), P3 might select CBA, the only remaining option that ranks $\mathrm{C}$ first. With the remaining preferences unaffected, and once again assuming sincere voting, B would emerge the winner as against A and C, even though with the true ordinal rankings disclosed, A defeats B. If given the power, P2 might exclude ranking $\mathrm{CAB}$ because doing so is likely to produce a voting path leading to his preferred outcome, B, although the voting path does so at the expense of $\mathrm{P} 3$ who ranks $\mathrm{C}$ first and B last. Excluding CAB effectively prevents option A from winning even though that is the only option capable of defeating B.

In two important institutional contexts, the range criterion is relaxed as a means of ensuring collective outcomes even when members hold preferences for that cycle. As we have already seen, when institutions demand a choice among options, rules that meet the Condorcet criterion risk failing that institutional obligation. Parliamentary rules avoid motion and amendment procedures in favor of plurality voting for example when selecting committee chairs, even though the general rule for legislative business is motion and amendment. (Levmore 1989, p. 1031; Stearns 1994, p. 1265-66, n.173). This non-Condorcet rule effectively violates range by disallowing the final pairwise comparison needed to disclose that, while the process has yielded 
an outcome, when all binary comparisons are assessed, the members' preferences cycle. In effect, some members are prevented by vote orders from expressing preferences for all candidates in any order of their choosing, thus violating range.

Appellate courts also relax range to meet their collective obligation to resolve properly docketed cases even when judicial preferences cycle. The Supreme Court's collective obligation to produce a judgment in a case that is properly before it, for example, prevents the Court from employing a case decision rule that satisfies the Condorcet criterion, although as we have seen this difficulty is substantially ameliorated by the companion narrowest grounds rule. (Stearns [2000] 2002, p. 154). When underlying judicial preferences are multidimensional and asymmetrical, however, and thus prone to a cycle over outcome and dispositive issues and thus when the narrowest grounds rule does not apply, a regime of unlimited pairwise comparisons by majority rule would threaten a collective impasse in the form of a cycle. The outcome voting rule thus ensures a judgment, but does so at the risk of suppressing majority preferences over some combination of issue resolutions. ${ }^{43}$

The preceding analysis does not imply that the Supreme Court is invariably obligated to produce a judgment, as, for example, when it determines that certiorari has been granted improvidently or when a pending case is remanded in light of a recently issued governing opinion. And of course the Court need not resolve issues in the manner preferred by the litigants. Appellate courts generally lack the degree of agenda control through the certiorari process that characterizes the Supreme Court. Even in the Supreme Court, however, each decision making juncture-from deciding whether to decide a case, to deciding whether a case is justiciable, to deciding the merits of a case-requires some formal, if de minimis, collective institutional decision. In the event that the judicial preferences cycled, a regime that adhered to range would 
instead threaten an impasse.

In addition to the companion outcome voting and narrowest grounds rules applied within individual cases, the Court has also developed a similar pair of companion rules that apply over larger numbers of case. In groups of cases over time, which create the risk of cycling even over separate majority opinions, ${ }^{44}$ the Court employs the doctrine of stare decisis. The presumptive obligation to adhere to precedent is the judicial equivalent of a time honored cycle breaking rule, namely preventing reconsideration of alternatives defeated in the past. The effect of the rule is to ground doctrine in the order of case presentations and, as such, the rule produces the risk that ideological interest groups will seek to manipulate the path of precedent. Once again, the Court ameliorates this problem with a companion rule, or set of rules, this time taking the form of standing. (Stearns [2000] 2002, pp. 160-64). The various standing rules-requiring injury in fact, causation, redressibility and presuming against third party and diffuse harm standingroughly translate to a requirement that fortuitous historical events beyond the control of the litigants themselves govern the critical path of case law. While the result remains path dependent, this regime has the benign effect of raising the cost of deliberate path manipulation. Once again, this renders the overall process more fair and the appearance increasingly legitimate. These combined rules, stare decisis and standing, improve the fairness and rationality of outcomes in parallel fashion to the companion outcome voting and narrowest grounds rule operating within individual cases.

Once again, range marks a critical distinction between rules employed in appellate courts and legislatures, including the Supreme Court and Congress. While Congress is generally able to avoid collective action and is thus better suited to employing rules satisfying the Condorcet criterion, for example motion and amendment voting, as we have seen, this should not suggest 
that legislative preferences endlessly cycle. The combination of structure induced equilibrating rules and logrolling, which allows members to register intensities of preference, is capable of generating preferred equilibrium results, perhaps at the expense of potentially thwarting Condorcet winners. Such devices include elaborate committee structures, bicameralism, filibusters and formal limits on the number of permissible amendments for pending legislation. (Shepsle \& Weingast 1981, pp. 503-17). Limiting permissible amendments relative to potential options violates the Condorcet criterion and thus this practice also relaxes range. Other equilibrating rules, even if not formally limiting votes relative to options, can impose effective limits simply by raising the cost of identifying all preferences, including those that if included in the mix would yield a cycle.

Even with these combined institutional arrangements, Congressional rules prove more resilient in satisfying the Condorcet criterion than do those in the Supreme Court. Through informal means, members of Congress can locate Condorcet winners informally even when formal rules appear to limit all necessary binary comparisons over options. When stakes are sufficiently high, members of Congress can negotiate outside formal voting and thus reveal preferences that encourage inaction or discourage adverse voting paths. In contrast with the Supreme Court, which is generally obligated to issue judgments in cases properly before it, Congress has no parallel obligation even to vote as an institution on each bill that is proposed. Instead, Congress allows countless legislative proposals never to become bills and the vast majority of bills that are proposed simply to die.

In addition, Congressional practices sometimes improve the quality of outputs by avoiding the Condorcet criterion in favor of other norms. Remember that the Condorcet criterion does not account for intensities of preference. In a group with the following ordinal preferences, 
P1: ABC; P2: BCA; and P3: CBA, while B is the Condorcet winner, it might also be an inferior social alternative to another option, for example, C. If, for example, P1 is nearly indifferent among all options, she might happily forego voting for $\mathrm{B}$ in a contest with $\mathrm{C}$, thus allowing $\mathrm{C}$ to prevail in exchange for the support of P2, who least prefers option A, in some other matter. Thus, through the commodification of preferences, legislators sometimes produce results that, while thwarting the Condorcet criterion, are nonetheless beneficial for all participants to the exchange.

Unanimity and independence of irrelevant alternatives: Unanimity is defined as follows: 'If an individual preference is unopposed by any contrary preference of any other individual, this preference is preserved in the social ordering.' (Stearns [2000] 2002, pp. 88, 347 n.112). While unanimity is equivalent to the efficiency criterion of Pareto superiority, a foundational definition of microeconomic efficiency, the different contexts in which these terms apply have the potential to invite some confusion. Within the study of private markets, a move from the status quo to an alternative state is defined as Pareto superior if it benefits at least one participant without harming others. An outcome is Pareto optimal if no further Pareto superior moves are available, meaning that all potential welfare improving moves have already taken place. (Calabresi 1991, p. 1212). At this point, any further changes from the existing allocation of resources will necessarily have distributional consequences, benefitting some at the expense of others.

Welfare economists generally regard private markets as uniquely well suited to producing wealth by facilitating Pareto superior transactions. The underlying intuition is that if we set aside such problems as initial wealth endowments and externalities and assume away illegal or coercive tactics, such as fraud or duress, then it is a fair supposition that market transactions are unanimously entered into by participants. Because people voluntarily engage in market exchange, it is also fair to assume that they do so with the intent to improve their position. 
Private market exchanges are thus likely to improve the utility of at least one and probably both parties to the resulting exchange. If that were not the case, the parties would not have bothered.

The difficulty with applying the Pareto criterion in the context of lawmaking is that mutually assented to trade in legislatures, or logrolling, has the potential to inhibit wealth producing private market exchange. As Oliver Wendel Holmes famously observed, 'Regulation means the prohibition of something.' (Hammer v. Dagenhart, 247 U.S. 251, 277 (1918) (Holmes, J., dissenting)). Regardless of the wisdom of the underlying regulatory policy, legislation that restricts private market transactions elevates legislative unanimity over private market unanimity. After all, for most regulatory policies to succeed, they must inhibit at least some potential private market transactions that might be characterized as Pareto superior. Conversely, constitutional doctrines that invalidate such regulation elevate private market unanimity (or Pareto superiority) over legislative unanimity. ${ }^{45}$

The contrast between the 1905 decision, Lochner v. New York, 198 U.S. 45 (1905), which marked the height of economic substantive due process, and the 1937 decision, West Coast Hotel v. Parrish, 300 U.S. 379 (1937), which marked the doctrine's decline, reveals the tension. The Lochner regime, which identified a fundamental right to contract, ensured adherence to a certain category of private market exchange, specifically contracts for bakers in labor markets, despite legislative market exchange resulting in progressive regulatory policies seeking to restrict those markets. Conversely, the West Coast regime, which marked the end of the period of economic substantive due process, elevated the power of legislative markets to agree upon restricting a similar category of private market exchange, this time involving working conditions for women. Of course even in the heyday of Lochner, certain private market exchange fell within the police power of states to regulate, including prohibitions against unlicensed practice of medicine and 
law and contracts for the sale of certain drugs, alcohol, gambling and sexual services. These cases simply raised the question whether regulating labor contracts on the ground of public health and safety should be added to the list of state police powers or removed under the guise of a constitutional rule. ${ }^{46}$ The critical point is simply this: The answer to this question cannot rest upon an objective application of the Pareto principle without first deciding in which sphereprivate markets or legislative markets—it is to be applied.

To be sure, an extensive public choice literature posits that legislative processes at both the federal and state levels are systematically biased in favor of regulatory policies that tend to undermine private market efficiency. (Aranson et al. 1983, pp. 10-14). As Einer Elhauge has persuasively argued, however, any such claim necessarily rests upon some unstated normative baseline assumption as to the appropriate extent of interest group involvement in political processes. (Elhauge 2008, pp. 264-72). While interest group theory does not help to answer this baseline question, social choice might prove of some value in at least exposing the inevitable tradeoffs among the plausible baselines when assessing institutions and the quality of their processes and outputs.

To fully appreciate unanimity, we must now introduce another Arrovian fairness condition, namely Independence of Irrelevant Alternatives. The criterion is defined as follows: 'The social choice between any two alternatives must depend only on the orderings of individuals over these two alternatives, and not on their ordering over other alternatives.' (Stearns [2000] 2002, pp. 89, 348 n.119). Independence requires that each decision maker base her choice between each pair of presented alternatives solely upon the relative merits of those alternatives, without strategic considerations. Prohibited strategies can include trying to anticipate, and thus derail, a disfavored voting path by voting other than for one's first choice as 
needed to prevent an adverse outcome or otherwise trying to improve one's utility through vote trading.

The independence criterion might well be the most counterintuitive and, indeed, controversial, of Arrow's fairness assumptions. The objection to independence can be expressed quite simply: If a decision maker is influenced in choosing between options A and B by the presence (or absence) or option $\mathrm{C}$, who is to say that $\mathrm{C}$ is irrelevant to that decision such that the decision maker should disregard this additional information? Despite this objection, both Condorcet and Arrow embraced independence, albeit for different reasons. Condorcet's intuition might prove more significant in evaluating Congress, while Arrow's intuition might prove more significant in evaluating the Supreme Court.

As we have seen, range is relaxed in the Supreme Court, which is generally obligated to ensure collective judgments in each case, whereas range is generally honored in Congress, which has the power to remain inert when preferences cycle or to commodify preferences when cyclical preferences fail to capture the real stakes due to different preference intensities. The intuition underlying Arrovian independence is largely opposite in these two institutions. Subject to a caveat described below, Supreme Court justices are generally presumed to adhere to independence, while members of Congress are understood routinely to violate independence.

Influenced by the republican philosopher, Jean-Jacques Rousseau, Condorcet proposed that in choosing among options, legislators should focus solely upon the merits of presented alternatives so that in each successive contest better options are selected until the best option emerges. (Stearns 1994, p. 1250 n.108). In Condorcet’s understanding, individuals, upon entering the public sphere either as legislators or as voters, are expected to subordinate their personal objectives in favor of their assessment of the best interest of society. (Baker 1975, p. 
230). In contrast, Arrow's intuition is more obviously influenced by the foundational assumptions of welfare economics. Arrow claimed that independence was necessary to avoid the difficulty based upon a common supposition among economists that government regulators confront potentially insurmountable difficulties in seeking to compare interpersonal utilities. (Mueller 2003, pp. 590-91). Of course in markets individuals routinely signal their own relative utility through their willingness to pay, or what economists label 'revealed preferences.' (Georgescu 2005, p. 259; Samuelson 1938, pp. 61-71). Indeed, to that extent, social choice theory provides a basis for understanding the comparative advantage of markets, when standard assumptions apply, in the creation of wealth, as compared with other institutions. The problem that Arrow sought to avoid was developing a rulemaking system that required a mechanism for evaluating relative utility in the absence of a pricing mechanism which allows individuals to express cardinal utility. The difficulty is that, absent a pricing mechanism, systems that seek to quantify and compare interpersonal utilities are likely to invite posturing or other forms of strategic behavior.

The unanimity and independence criteria operate in tension. The difficulty is that within legislatures individual legislators enter into unanimous exchange or logrolls by agreeing to vote strategically rather than sincerely on the merits of each proposal. The logrolling process demands careful attention to voting agendas and considerable foresight about the relationships between future options and immediate decisions. The job of legislating demands skill in vote trading and strategizing. Thus, while logrolling promotes unanimity, it thwarts independence. Conversely, norms against strategic judicial voting promote independence (an element of principled voting) at the price of sacrificing potentially unanimous vote trades that would improve the likelihood of ruling closer to the ideal point of the participating jurists. (Cooter 2000, pp. 205-09). 
Most commentators presuppose that judges engage in principled, rather than strategic, decision making. And yet despite this general understanding, it would be hard to argue that courts as institutions, in contrast with legislatures, are somehow unable to incorporate vote trading into their decision making processes. Appellate courts have fewer members than most legislative bodies and the judges, who acquire substantial information regarding each others' preferences, anticipate repeat rounds of play. Given that the circumstances are ripe for enforcing agreements, it is not difficult to imagine incorporating a judicial custom or norm that would facilitate some form of logrolling. And yet, even in such a high stakes context as the Supreme Court we do not see such a regime. ${ }^{47}$

To be sure, recent studies of the papers of retired Supreme Court justices demonstrate that individual justices often change their positions between their initial case assessments, as indicated in their preliminary post-argument conference votes, and the final case dispositions. (Epstein \& Knight 1998, pp. 4-9, Maltzman et al. 2000, p. 7). This tends to happen when justices need to compromise to secure a majority, without which the case would produce a holding but not establish a precedent. The result is often to produce a narrower holding, quite possibly a Condorcet winner, than the preferred broader holding of the justice willing to compromise. (Stearns 2000, pp. 326-27).

And yet, it is hard to locate any specific examples of vote trading among the justices across cases or even across issues within cases. One obvious inhibiting norm is opinion writing. In fact, the custom of written opinions by appellate court judges might inhibit strategic voting by providing a written record, if a fragmented one, of the justices ordinal rankings over various doctrinal alternatives. (Stearns [2000] 2002, p. 92). Departing from such expressed rankings, at least absent a contrary ruling or some other compelling justification for doing so, invites 
criticism among other justices, the media and academic commentators. This is not to suggest that jurists never stray from prior statements on the requirements of law, but it does suggest that doing so is not costless.

In contrast, it is widely understood that legislators vote for or against bills for any number of reasons that can include, but are by no means limited to, the merits of presented alternatives. We also do not see members of Congress justifying their votes in writing. This contrary practice might suggest that legislators sometimes, or often, vote for or against proposed legislation for reasons other than a principled commitment to the cause.

Nondictatorship: Nondictatorship is defined as follows: 'No individual enjoys a position such that whenever he expresses a preference between two alternatives and all other individuals express an opposite preference, his preference is always preserved in the social ordering.' (Stearns [2000] 2002, pp. 92, 339 n.130). Nondictatorship appears the most obvious fairness condition in any collective decision making institution. In fact, however, Arrow's Theorem proves that, to preserve transitive orderings in a system that meets the other fairness conditions set out above, it is inevitable that someone be vested not merely with substantially disproportionate decisional authority, but with authority that violates nondictatorship. While it is certainly true that not all Supreme Court justices or members of Congress have equal power in their respective institutions, as a formal matter, both institutions satisfy the nondictatorship criterion. Although institutional practices vest disproportionate power in particular members, based for example on seniority status, these customs or rules do not give decisive significance to one participant at the expense of the contrary preferences of all members, at least not all of the time. And thus, no dictator's contrary preference is consistently preserved in the social ordering at the expense of the preferences of the remaining members. 
That said, it is worth discussing the occasional unequal power distributions within these institutions. In the Supreme Court, as in most appellate courts, the Chief Justice (or in the case of the federal circuits, the chief judge) truly is the first among equals in terms of the weight attached to his or her vote. $^{48}$ Even so, the Chief Justice does possess a significant source of disproportionate power, which occasionally vests to other senior members of majority coalitions. When the Chief Justice votes with the majority, he assigns the opinion; when the Chief Justice votes in dissent, the senior Justice voting with the majority assigns the opinion. (Brenner \& Spaeth 1988, p. 72). While this practice does not violate nondictatorship, the power differential is notable. ${ }^{49}$ More obviously, a minority of four is given power to control the Court's docket through the writ of certiorari. This also does not defy Arrovian nondictatorship because the Rule of Four, which governs the grant of certiorari, does not vest the same four justices with power over all certiorari petitions against the contrary will of the Court. (Stearns 1995a, pp. 1350 n. 124, 1369). Those in a successful minority of four in one round might well find themselves in the unsuccessful majority of five in the next. Setting these practices aside, Supreme Court justices generally hold equal voting power.

Within Congress, the various structures that allow individual members to block legislation afford such members disproportionate power relative to their colleagues. While each member has an equal vote as a formal matter, Congress effectively allows some members to exert more power than their nominal votes might otherwise suggest. But here too, the power is not unlimited. As discussed above, in the event that a powerful committee chair abuses his or her power, other members can engage in a variety of retaliatory measures intended to limit such abuses in the future. The following table summarizes the preceding discussion and analysis.

\section{Table 3}




\section{The Supreme Court and Congress through an Arrovian Lens}

\begin{tabular}{|c|c|c|}
\hline $\begin{array}{l}\text { Arrovian } \\
\text { Criterion }\end{array}$ & Supreme Court & Congress \\
\hline Range & $\begin{array}{l}\text { Collective obligation to } \\
\text { resolve properly docketed } \\
\text { cases generally prevents } \\
\text { the Supreme Court from } \\
\text { employing Condorcet- } \\
\text { producing rules. Condorcet } \\
\text { rules, are, however, paired } \\
\text { with other rules that ensure } \\
\text { outcomes, for example } \\
\text { outcome voting and the } \\
\text { narrowest grounds rule, } \\
\text { and stare decisis and } \\
\text { standing. }\end{array}$ & $\begin{array}{l}\text { Collective ability to remain inert } \\
\text { generally allows Congress to employ } \\
\text { rules that tend toward the Condorcet } \\
\text { criterion. Other practices allow } \\
\text { members to register cardinal } \\
\text { preferences, thus promoting preferrer } \\
\text { results that sometimes thwart the } \\
\text { Condorcet criterion. }\end{array}$ \\
\hline Unanimity & $\begin{array}{l}\text { Certain practices, including } \\
\text { publication of opinions, } \\
\text { inhibit vote trading in the } \\
\text { Supreme Court, at least } \\
\text { across cases, although } \\
\text { justices sometimes } \\
\text { compromise to form } \\
\text { majorities as needed to } \\
\text { give cases precedential } \\
\text { status. }\end{array}$ & $\begin{array}{l}\text { Vote trading is encouraged or at } \\
\text { least condoned, thus facilitating } \\
\text { Pareto superior legislative } \\
\text { exchanges, although such } \\
\text { legislative exchange has the } \\
\text { potential to produces regulation } \\
\text { that inhibits private market } \\
\text { exchange. }\end{array}$ \\
\hline $\begin{array}{l}\text { Independence } \\
\text { of irrelevant } \\
\text { alternatives }\end{array}$ & $\begin{array}{l}\text { The same practices } \\
\text { described above promote } \\
\text { judgment based judicial } \\
\text { decision and thus raise the } \\
\text { costs of strategic voting } \\
\text { among justices; strategic } \\
\text { interactions that remain } \\
\text { tend to push toward } \\
\text { median position on the } \\
\text { Court or otherwise to } \\
\text { promote majority opinions. }\end{array}$ & $\begin{array}{l}\text { Members regularly vote } \\
\text { strategically, thus cardinalizing } \\
\text { their preferences over issues and } \\
\text { bills, and thus violate the } \\
\text { independence criterion. }\end{array}$ \\
\hline Nondictatorship & $\begin{array}{l}\text { While opinion assignment } \\
\text { power affords } \\
\text { disproportionate power to } \\
\text { the Chief Justice (or the } \\
\text { senior majority justice), as } \\
\text { a formal voting matter, the } \\
\text { Supreme Court adheres to } \\
\text { nondictatorship. }\end{array}$ & $\begin{array}{l}\text { Compromised by practices that } \\
\text { afford disproportionate power to } \\
\text { committee chairs and to individual } \\
\text { members of Congress. And yet, } \\
\text { these formal practices are limited } \\
\text { by informal quasi-market checks } \\
\text { when the stakes are sufficiently } \\
\text { high to overcome limits on voting. }\end{array}$ \\
\hline $\begin{array}{l}\text { Condorcet } \\
\text { Criterion }\end{array}$ & $\begin{array}{l}\text { Evolution of important } \\
\text { rules, including outcome } \\
\text { voting and stare decisis are } \\
\text { attributable to the Court's } \\
\text { general inability to employ } \\
\text { Condorcet-producing rules. }\end{array}$ & $\begin{array}{l}\text { Important congressional voting } \\
\text { rules have evolved toward } \\
\text { Condorcet criterion, except when } \\
\text { Congress lacks the power to } \\
\text { remain inert, including when } \\
\text { choosing legislative leaders. Some }\end{array}$ \\
\hline
\end{tabular}




\begin{tabular}{l|l|l}
\hline & These rules must be & limiting rules appear to defy \\
evaluated in conjunction & Condorcet criterion, but common \\
with companion rules, e.g., & voting practices provide quasi- \\
the narrowest grounds rule & and standing, which help to & Conket solution, thus restoring \\
improve the Court's & Condorcet-criterion when stakes \\
averall rationality and & aigh. \\
fairness. & \\
\hline
\end{tabular}

VI. Conclusion and directions for future scholarship

This chapter has offered an introduction to how to apply Arrow's Theorem and social choice to the study of lawmaking institutions and rules, with a particular focus on those in the United States. While numerous scholars have incorporated social choice into their study of law and legal institutions, the promise of further work remains. This chapter offered a few modest suggestions for those interested scholars seeking to use these powerful tools in the study of law. Any lack of prescience should not be construed to discourage applications by more creative minds.

Identifying private law rules that ameliorate cycling: This chapter identified a few rules that seem motivated to avoid institutional cycling, including off the rack rules of inheritance and contract damages rules. Certainly there are others, and studies that identify such rules would lead to deeper understandings of institutions. Examples include rules governing the discharge of various forms of debt in bankruptcy, joinder rules in civil procedure and settlement rules in class action and in nonclass action complex litigation.

Identifying the rules that promote principled or strategic decision making: While this chapter identified illustrations in the context of judicial and legislative decision making, studying other institutional contexts, including voting in corporate law, agreements within various community organizations and decision making on various boards will provide the basis for 
understanding the objectives and capacities of these and other institutions.

Evaluating the role of consensus in various institutional contexts: To what extent do international organizations, which have relatively loose legal structure and enforcement mechanisms, rely upon consensus as the prerequisite to achieving collective action? Candidates for study include the United Nations, NAFTA, GATT and the European Union.

Studying the levels at which decisions can be made as a mechanism of social choice: While numerous studies evaluate particular institutions, and even multiple institutions within a common level of government, to what extent might social choice explain federalism, domestically and internationally? Are there factual contexts that are conducive to cycling or path dependent outcomes at one level of governance that might conduce to more stable Condorcet winning outcomes when the level of government shifts? If so, how do institutional mechanisms optimize the level of decision making?

This is by no means an exhaustive list, and of course scholars should approach these or other topics with considerable care. Social choice and the impossibility theorem in particular have a seductive quality; they are, after all, about inevitable tensions that arise when we structure institutions that govern our interactions with others. And yet, when we recognize the inherent limitations of this (or any other economic) discipline, as a tool of analysis, it proves quite powerful.

\footnotetext{
${ }^{1}$ Portions of this chapter are adapted from the following works: Maxwell L. Stearns, The Misguided Renaissance of Social Choice, 103 Yale L.J. 1219 (1994), an Article previously published in the Yale Law Journal, reprinted with permission of The Yale Law Journal, Company, Inc. and The William S. Hein Company; Maxwell L. Stearns \& Todd Zywicki, Public Choice Concepts and Applications in Law, chapter 3 (forthcoming West Publishing Company 2009), with permission from Thomson Reuters; Maxwell L. Stearns, Constitutional Process: A Social Choice Analysis of Supreme Court Decision Making (Ann Arbor: The University of Michigan Press, 2000), chapter 2, with permission, Copyright (c) by The University of Michigan Press 2000. I will also reference these and related works where appropriate.

${ }^{2}$ Marbury Research Professor of Law, University of Maryland School of Law. The author thanks Todd Zywicki for
} 
his helpful comments, and Brandon Draper, David Myers, and Heather Pruger for valuable research assistance and editing suggestions. The research support of the University of Maryland School of Law is appreciated.

${ }^{3}$ While space constraints prevent a complete response to all normative proposals described in part III, the analytical tools introduced in part III can be extended to address others beyond those specifically addressed.

${ }^{4}$ The sincere voting assumption is consistent with Arrow's condition of Independence of Irrelevant Alternatives. (Stearns [2000] 2002, pp. 89-92).

${ }^{5}$ See infra Part V.B. A small exception exists for rules that couple the Condorcet rule with an alternative default rule that applies in the absence of a Condorcet winner. (Nurmi 1983, p. 188). While such rules are of theoretical interest, they are administratively impractical and thus will not be further considered here.

${ }^{6}$ We have already seen the path leading to C. If, instead, the agenda setter most prefers option A, she would first present B versus C (B wins), then B versus A (A wins). Option C, the sole option that would defeat A in a direct pairwise contest was defeated in the first round. And if the agenda setter most preferred option $B$, she would first present $C$ versus $A$ ( $C$ wins), and then present $C$ versus $B$ ( $B$ wins). In this example, option $A$, the sole option that would defeat option B in a pairwise contest, was defeated in the first round.

${ }^{7}$ For example, see Levmore 1989, pp. 994-96 (explaining evolution of parliamentary rules of order away from motion and amendment voting in circumstances in which the protocol is likely to afford committee chairs substantial agenda setting authority), Stearns 1995a (describing standing rules as a method by which the Court limits agenda setting power over developing legal doctrine by ideological interest groups) and Stearns 1995b (providing historical support for social choice account of standing doctrine).

${ }^{8}$ Of course within markets, the price system allows the robust cardinalization of preferences. In comparison, legislative vote trading is akin to a more primitive barter system that allows substantial, but less fluid, cardinalization. For a recent article that claims cardinal preference can be used to meet Arrow's fairness conditions plus rationality, see Vasiljev 2008. Of those, the difficult question remains of how to facilitate meaningful cardinalization in various institutional settings.

${ }^{9}$ The discussion of Arrow's Theorem that follows will demonstrate that Condorcet's insights about group decision making and cycling form the foundation for a broader set of inquiries about the nature of social choice and institutional decision making rules. A later discussion, see infra part $\mathrm{V}$, revisits these criteria in more detail and offers specific applications to various institutional settings.

${ }^{10}$ For a discussion of the relationships between the criteria described in this chapter, based upon William Vickrey's simplified proof and the original Arrow's Theorem criteria, see Stearns [2000] 2002, pp. 337 n.22, 344-45 n.91, 346-47 n.104, 347-48 n.112; Arrow 1951; Arrow 1963; Vickrey 1960, pp. 507-35.

${ }^{11}$ To be clear, this does not mean that outcomes cannot favor numerical minorities, racial or otherwise, without violating Arrow's fairness criteria. Quite the contrary, an institution meeting some combination of Arrow's fairness plus rationality conditions is potentially capable of furthering any normative policy whether involving antidiscrimination, affirmative action or something else entirely.

${ }^{12}$ While this appears intuitive, that should not imply that it is universally correct. As explained below, there might be circumstances in which one (or more) members holding an extreme position favors the opposite extreme to the moderate position.

${ }^{13}$ As Levmore observes, this explains a common feature in parliamentary decision making, namely that to limit the power of committee chairs to favorably order motions, such rules generally impose a sequencing process when options can be readily cast along a single normative scale, for example in the selection of dates or budgetary allocations. (Levmore 1989, pp. 1029-31).

${ }^{14}$ This is also referred to as the Hotelling principle. (Hotelling 1929; Congleton 2003).

${ }^{15}$ For an analysis of how two staged elections in the United States produce substantial policy distance between Democratic and Republican Candidates, see Stearns and Zywicki 2009, chapter 6.

${ }^{16}$ For a table that illustrates that the probability of profiles without a Condorcet winner increases as a function of increasing options and increasing decision makers, see Riker 1988, p.122.

${ }^{17}$ Ordeshook observed that 'the existence of multipeaked preferences implies that the issue space is not unidimensional, but multidimensional.' (Ordeshook 1986, pp. 164-65).

${ }^{18}$ To simply the visual presentations of relationships among options, the graphics use continuous lines to connect discrete utilities assigned to each alternative. This should not be interpreted to imply that the utilities are continuous between selections among discrete options.

${ }^{19}$ And indeed, with two options and an odd number of decision makers, plurality rule and the Condorcet criterion 
coincide. With more options, however, these criteria split and decision makers must elect which sets of costs and benefits are more important in electing between these two rules.

${ }^{20}$ As Tonja Jacobi observes, for individual justices who hold a specific view of constitutional interpretation, for example Hugo Black who professed a rigid textualism, standard assumptions about preferring liberal to moderate to conservative positions (or the reverse) might not hold. Jacobi 2009a, p.29. In a separate work, Jacobi demonstrates that when the Court is concerned about producing a supermajority opinion, this strengthens the relatively bargaining position of non-median justices relative to that of the median justice. Jacobi 2009b. Of course, this implies that coalition members have secured the prior commitment of the median jurist or some other justice who provided the critical fifth vote; otherwise, the marginal justice would retain the essential bargaining leverage.

${ }^{21}$ While not discussed in this subpart, this stands in contrast with a regime of cumulative voting. In this regime, voters have a set number of votes over the slate of candidates and can elect to cast more than one of their votes, and even all of their votes, for a single candidate. Perhaps the most prominent recent proposal along these lines was advanced by Lani Guinier, who has advocated this regime in the context of municipal voting to allow minorities to ensure proportional representation. Guinier explains:

In the modified at-large election, candidates would run jurisdiction-wide, but the threshold for election would be reduced from $51 \%$ to something less. In the case of a four person at-large council, the threshold for election would be $21 \%$. Voters would be given the same number of votes as open seats (four in this case) that they could distribute by their choice among the competing candidates. If black voters are a politically cohesive interest constituency, they might use all four of their votes on one candidate. In a 100 voter jurisdiction, where each black voter gave all four of her votes to one candidate, a $25 \%$ black minority could elect a representative. The intensity of their interests and their political cohesion would ensure black voters at least one representative.

(Guinier 1994, p. 95).

${ }^{22}$ Samuel Merrill has provided a summary of the relative Condorcet efficiencies of various rules including several discussed above based upon the assumption of 25 voters and candidates from 2 to 10. (Merrill 1984, pp. 28-36). Merrill also compares these voting protocols, using the same assumptions, based upon what he terms utilitarian efficiency. For Merrill's purposes, Condorcet efficiency measures the percentage that the winner of all pairwise comparisons is also the winner of the entire election. Utilitarian efficiency measures the likelihood that a voting method yields a winner that receives the approval of the greatest number of voters. Merrill summarizes his results in two tables. (Merill 1984, pp. 28-36); Mueller 2003, pp. 150-51).

${ }^{23}$ For an introduction to this literature, see Stearns 1994, pp. 1227-33.

${ }^{24}$ For an earlier presentation of this example, see Stearns [2000] 2002, pp. 19-27.

${ }^{25}$ This includes assuming that the presence of an alarm does not signal higher value of contents in the home to steal.

${ }^{26}$ And indeed general and prospective rules can be welfare enhancing even if they are not optimal inasmuch as they create default rules that parties have the potential to negotiate around. For a general discussion, see Stearns \& Zywicki 2009, chapter 4 (describing such rules as illustrating battle of the sexes game).

${ }^{27}$ In the original story, an aging Lear vainly disinherits his youngest and most beloved daughter, Cordelia, because unlike her sisters, Goneril and Regan, Cordelia was unwilling to express her love for him in unconditional terms as a precondition to taking her share of the Kingdom. Cordelia claimed that while she dearly loved her father, her foremost love would be for her yet unchosen husband. As the story unfolds, we learn the devastating consequences of Lear's disinheritance of Cordelia and of his premature conveyance of the Kingdom to Goneril and Regan.

${ }^{28}$ After the 10/10/10 plan is submitted, Goneril can approach Regan, offering to cut Cordelia from the coalition and proposing an alternative (Goneril, Regan) coalition with a 15/15 split. That, of course, was the starting point in the prior example, which was not a stable solution.

${ }^{29}$ For ease of exposition, we assume immediate judicial enforcement.

${ }^{30}$ For a somewhat more complex presentation that explores the empty core bargaining game and its relationship to the Coase theorem, see Aivazian \& Callen 1981, Coase 1981, and Stearns 1994, pp. 1234-40.

${ }^{31}$ The same analysis applies with respect to the expectancy damages rule. Assuming that the legislators hold no stake in the outcome of any particular set of coalitions that form among siblings trying to negotiate in the absence of a will, the obvious facilitating rule restores the victim of a breach to her position absent the breach. This rule restores a stable outcome, albeit one that thwarts an available superior coalition, regardless of which coalition initially forms. To be clear, while each of these rules — equal division among siblings absent a will or expectancy damages — ensures 
a stable outcome, it remains possible that the eventual outcome can nonetheless be characterized in terms of a cycle. The outcome remains stable however because the legal rule ensures that there is no basis for supplanting the off the rack outcome (following the property rule) or that the cost of displacing an agreed upon outcome exceeds any resulting gain (following the contract rule) to the defecting party.

${ }^{32}$ Notice the theoretical connection to the claim relating cardinalized preferences to Arrow's Theorem. (Vasiljev 2008).

${ }^{33}$ Thus, the Oxford English Dictionary defines legitimate as 'to declare to be lawful, to cause to be regarded as lawful offspring,' and '[c]omfortable to law or rule; sanctioned or authorized by law or right; lawful; proper,' and further describes the etymology as follows: '[T] he word expresses a status which has been conferred or ratified by some authority.' (Simpson \& Weiner 1989, p. 811).

${ }^{34}$ Levmore, for example, suggests that thwarted majorities can informally discover that particular results produce avoidable dissatisfaction thus pushing some parliamentary rules toward motion and amendment voting, which satisfies the Condorcet criterion. (Levmore 1989, pp. 994-96).

${ }^{35}$ This is not to suggest, of course, that the Justices never engage in strategic behavior in their efforts to promote desired policy objectives in a given case. (Epstein \& Knight 1998). As explained infra Part III.B, and cites therein, such behavior is generally limited to compromise along a unidimensional issue continuum within a case, almost invariably toward the median, rather than across issues within a case or across cases.

${ }^{36}$ Farber and Frickey have relied upon such concepts as the Yolk, Covered Set, and Strong Point to explain why we do not observed cycling in legislatures. Although formally modeled somewhat differently, each concept rests on the intuition that legislative cycling is avoided in favor of a stable center of gravity that represents a set of outcomes capable of defeating most alternatives in direct comparisons. (Farber \& Frickey 1991, p. 54). The set of options that satisfy this criterion does not defeat all alternatives in direct comparisons. As a result, depending upon the stakes involved and the intensity with which a potentially thwarted majority prefers an alternative to an option falling, for example, within the yolk, this concept appears at most a partial account of the failure of observed legislative cycling. Alternatively, these authors have suggested that the desire to avoid cycling itself can prevent cycling. (Farber \& Frickey 1988, p. 434). For this thesis to succeed, the participants must value avoiding cycling sufficiently to change the nominal payoffs in a manner no longer characterized in terms of a cycle. If they do not, then the cycle persists, but if they do, the problem of cycling is avoided by assuming that the payoffs that conduce to cycling no longer exist.

${ }^{37}$ To be clear, thin versus thick markets is not a simple function of the number of participants, but also a function of the timing of market choice. Once parties have entered into a contract, especially one that requires long term performance, for example a service contract for an automobile or a contract to renovate a home, even parties that entered the contract with many choices concerning with whom to deal might suddenly find themselves in a bilateral monopoly, a paradigmatic "thin" market. For a general discussion, see Stearns 2003, pp. 92-96, and accompanying notes (collecting authorities).

${ }^{38}$ While the initial discussion of Arrow's Theorem, see supra part II.B, related the problem of cycling and the Condorcet criterion to a broader inquiry into social choice, the discussion that follows sets out detailed definitions of each term and applies the underlying concepts to specific institutions.

${ }^{39}$ For a discussion of Arrow's initial results and how Arrow corrected an initial error, see Stearns 2000 [2002], pp.334-35 n.91. With one exception, explained in Stearns 2000 [2002], pp.346-47 n.104 (discussing range condition), following Mueller 2003, I am employing the definitions from William Vickrey's more accessible proof (Vickrey 1960, pp. 507-09), in lieu of those set out in Arrow's revised proof. For an explanation, including a comparison to Arrow's original and revised proofs, see Stearns [2000] 2002, pp. 344-45 n.91, 346-47 n.104, 34748 n.112.

${ }^{40}$ William H. Riker, for example, strongly questioned the validity of independence of irrelevant alternatives. (Riker 1982, pp. 100, 130). Richard Pildes and Elizabeth Anderson have questioned the validity of collective rationality or transitivity. (Pildes \& Anderson 1990, pp. 2146-58, 2192). For a response to these arguments, see supra note Error! Bookmark not defined. and cites therein.

${ }^{41}$ See supra note 39, and cites therein (describing differences between Arrow's revised proof and Vickrey's simplified presentation of Arrow's Theorem).

${ }^{42}$ For a discussion of how the narrowest grounds rule operates to locate available Condorcet winners even when there is no majority first choice opinion, see Stearns [2000] 2002, pp. 124-39 (discussing narrowest grounds doctrine) and Stearns \& Zywicki, chapter 7 (The Judiciary). 
${ }^{43}$ For illustrations, see Stearns [2000] 2002, pp. 97-157. It is also worth noting that in cases where the Court splits over three judgments, it is possible that the outcome voting rule will not yield a majority for a preferred judgment. As a practical matter, the Court has avoided this difficulty in virtually every case to present the difficulty by an informational accommodation in which a justice or group of justices embracing a more extreme position, affirm or reverse, instead opts for the median remand position to achieve a judgment. (Stearns [2000] 2002, pp. 53-54).

${ }^{44}$ For an illustration, consider Crawford v. Board of Education, 458 U.S. 527 (1982) and Washington v. Seattle School District No. 1, 457 U.S. 457 (1982). In these two cases decided on the same, separate majorities resolved each opinion in seemingly opposite fashion despite an overlapping suppressed majority that favored consistent treatment. For a more detailed presentation and analysis, see Stearns [2000] 2002, pp. 24-30. The analysis demonstrates that with sincere voting and stare decisis, had the cases been presented a year apart, the order of presentation would have determined the outcome in both cases as the issue in the second case would not have been the original merits, but rather whether the prior case governed as precedent. (Stearns [2000] 2002, pp. 24-30). ${ }^{45}$ To be clear, legislative decision making requires approval by majority rule, and not unanimous legislative consent. The unanimity criterion, however, does not apply at the level of final legislative approval, but rather at the level of individual logrolls. For this reason, private market transactions proceed with a lower level of consensus than legislative transactions. When two private market actors unanimously transact business, then barring any legal prohibitions to the deal, the exchange proceeds. There is no need for additional consent by other market participants. In contrast, when two legislators engage in a logroll through their unanimous consent, that exchange acquires no force unless and until it is ratified by several majority voting procedures that incorporate it into a successful bill. The level at which the unanimity criterion is applied in the two settings is not the ratification of the exchange or the vote trade, but rather the exchange or vote trade itself.

${ }^{46}$ This is not to suggest that other substantive considerations might not have motivated the enactment of such labor laws. (Stearns \& Zywicki 2009, chapter 2 (Interest Group Theory \& Rent-Seeking)).

${ }^{47}$ For an illustration of a rejected overture by Justice Brennan to Justice Powell offering to abandon the de facto/de jure distinction in deciding Keyes v. School District No. 1, 413 U.S. 189 (1972), as Powell preferred, in exchange for Powell's joining the proposed majority opinion despite language on busing that Powell found objectionable, see Jeffries 1994, pp. 303-04. While justices sometimes do compromise to produce majorities within cases as needed to give a case precedential status, there is scant, if any, evidence of judicial vote trading among justices across cases. ${ }^{48}$ Compare, for example, this power to that of the Vice President in his capacity as President Pro Tem of the Senate, under which in the event of a tie, he casts the deciding vote.

${ }^{49}$ For example, the practice does violate the Anonymity criterion of May's Theorem, which holds that ' $D$ is determined only by the values of $\mathrm{D}_{\mathrm{i}}$, and is independent of how they are assigned. Any permutation of these ballots leaves D unchanged.' (Mueller 2003, pp. 133-36). May’s Theorem holds that only simple majority rule satisfies the conditions of decisiveness, anonymity, neutrality and positive responsiveness. (Mueller 2003, pp. 133-36).

Table 2, Figures 1, 2 and 3 and Bibliography are attached below. 
Table 2

Values of $p(\mathrm{n}, \mathrm{m})$ : Proportion of Possible Profiles Without a Condorcet Winner

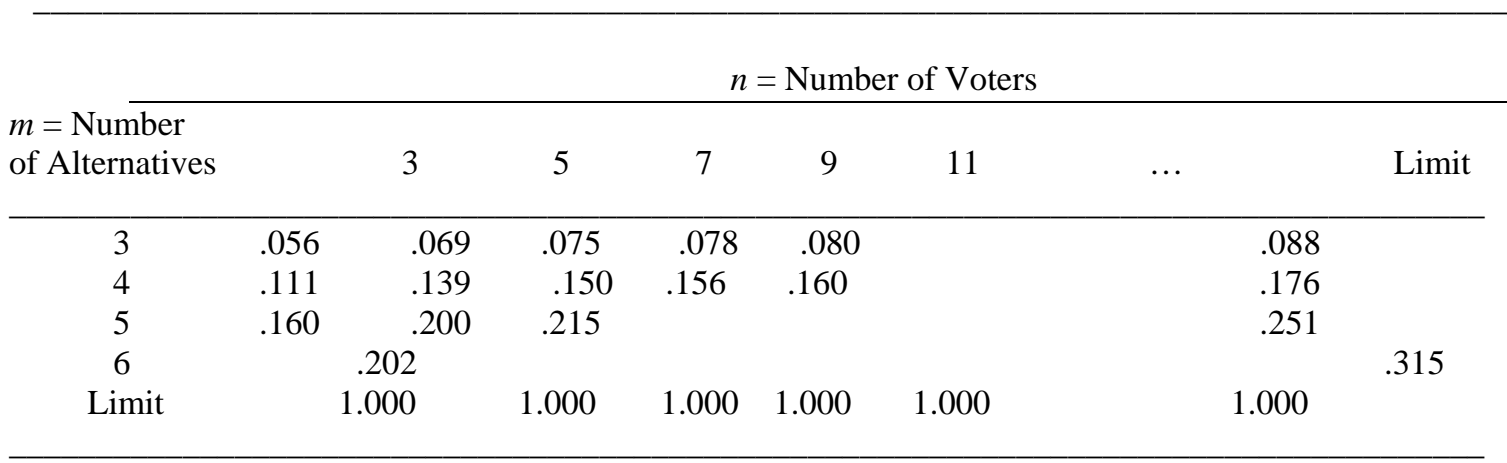

The entry in the row for four alternatives and in the column for seven voters-namely, .150-is the ratio of the number of profiles without a Condorcet winner to the number of profiles possible when seven voters order four alternatives.

Taken from William H. Riker, Liberalism Against Populism, A Confrontation Between the Theory of Democracy and the Theory of Social Choice 122 (1988). Reprinted with permission of Waveland Press. 


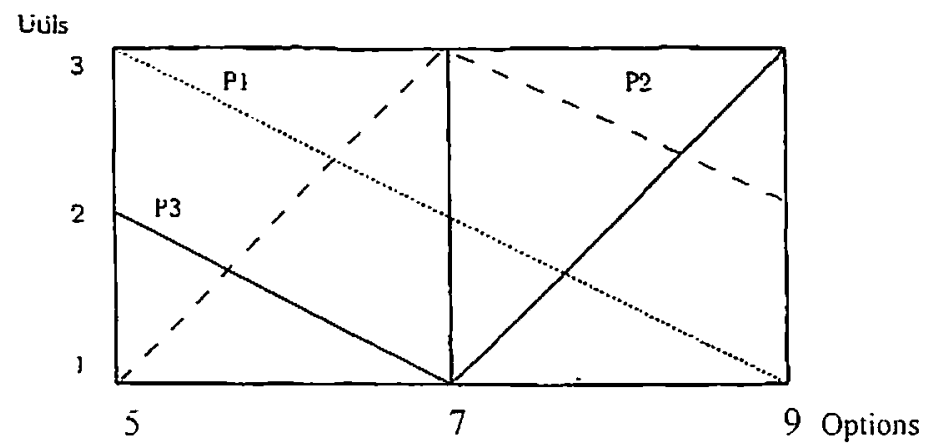

Fig. 1 Cycling in a Unidimensional issue continuum 


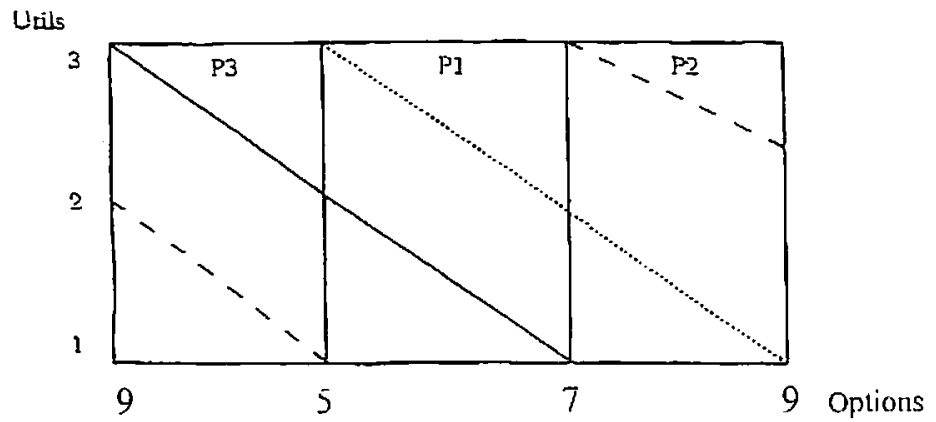

Fig. 2 Cycling in a multidimensional issue spectrum with asymmetrical preferences 


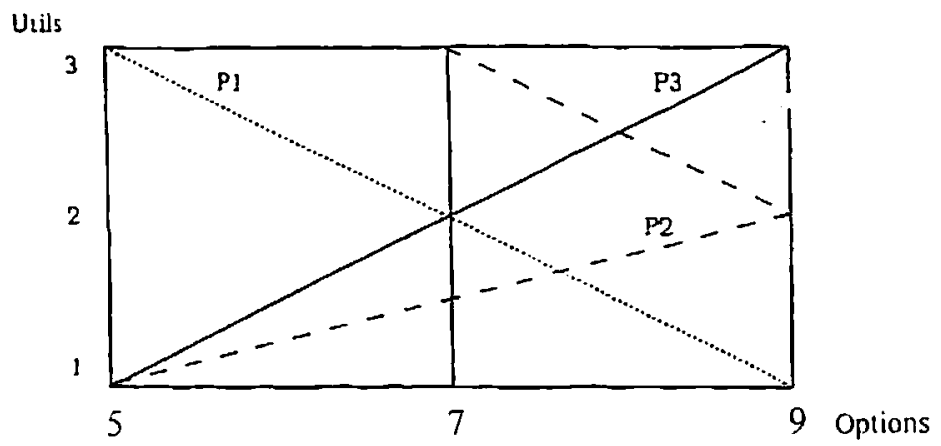

Fig. 3 Stable resolution with multidimensional and symmetrical preferences 
Bibliography

$\underline{\text { Books }}$

Arrow, Kenneth J. (1951), Social Choice \& Individual Values, reprinted (1963), US: John Wiley \& Sons.

Baker, Keith M. (1975), Condorcet: From Natural Philosophy to Social Mathematics, US: University of Chicago Press.

Calamari, John D. and Joseph M. Perillo (4th ed. 1998), The Law of Contracts § 14.4, US: West Group, pp. $543-46$.

Congleton, Roger (2003), C.K. Rowley and F. Schneider (eds), 'The Median Voter Theorem', in The

Encyclopedia of Public Choice, US: Kluwer Academic Publishers.

Cooter, Robert D. (2000), The Strategic Constitution, US: Princeton University Press, pp. 205-09.

Epstein, Lee and Jack Knight (1998), The Choices Justices Make, US: CQ Press 1998.

Farber, Daniel A. and Philip B. Frickey (1991), Law \& Public Choice: A Critical Introduction, US: University of Chicago Press.

Georgescu, Irina (2005), Luis Godo (ed), 'On the Notion of Dominance of Fuzzy Choice Functions \& its Application in Multicriteria Decision Making', in Symbolic \& Quantitative Approaches to Reasoning with Uncertainty, Germany: Springer-Verlag Berlin Heidelberg, pp. 257-68.

Golub, Sidney H. (2008), Kristen Renwick, Ronald Miller, Jermoe Tobis (eds), 'Stem Cell Politics: The Perfect is the Enemy of the Good', in Fundamentals of Stem Cell Debate: The Scientific, Religious, Ethical, and Political Issues, US: University of California Press, pp. 134-45.

Guinier, Lani (1994), The Tyranny of the Majority: Fundamental Fairness in Representative Democracy, US: Free Press.

Jacobi, Tonja (2009), The Judiciary, in The Elgar Handbook of Public Choice, Elgar Press 2009, p. 29 (Jacobi 2009a)

Jeffries, John C. (1994), Justice Lewis F. Powell, Jr., US: Macmillan Publishing.

Madison, James (1987), Isaac Kramnick (ed), 'The Federalist No. 10’, in The Federalist Papers, US: Penguin, pp. 122-27.

Maltzman, Forrest et al. (2000), Crafting Law on the Supreme Court: The Collegial Game, UK: Cambridge University Press.

Mueller, Dennis C. (2003), Public Choice III, US: Cambridge University Press.

McGovern, William M. (3d ed. 2004), 'Terminology and Choice of Law', in Wills, Trusts \& Estates: Including Taxation \& Future Interests, US: West, pp. 25-36.

Ordeshook, Peter C. (1986), Game Theory \& Political Theory: An Introduction, US: Cambridge University Press.

Riker, William H. (1982), Liberalism Against Populism: A Confrontation Between the Theory of Democracy \& the Theory of Social Choice, US: W.H. Freeman.

Shakespeare, William (1992), Jay L. Halio (ed), The Tragedy of King Lear, reprinted (2005), UK: Cambridge University Press. 
Simpson, John and Edmund Weiner (eds) (2d ed. 1989), 'Legitimate', in Oxford English Dictionary, US: Oxford University Press, p. 811.

Stearns, Maxwell L. (2002), Constitutional Process: A Social Choice Analysis of Supreme Court Decision Making, US: University of Michigan Press, pp. 41-94.

Stearns, Maxwell L. and Todd Zywicki (forthcoming 2009), Public Choice Concepts \& Applications in Law, US: West Publishing Co.

$\underline{\text { Periodicals }}$

Aivazian, Varouj A. and Jeffrey L. Callen (1981), 'The Coase Theorem \& the Empty Core’, J.L. \& Econ. 24 (1), 175-181.

Aranson, Peter H., et al. (1983), ‘A Theory of Legislative Delegation’, Cornell L. Rev. 68 (1), 1-67.

Brenner, Saul and Harold J Spaeth (1988), 'Majority Opinion Assignments and the Maintenance of the Original Coalition on the Warren Court', Am. J. Pol. Sci. 32 (1), 72-81.

Calabresi, Guido (1991), ‘The Pointlessness of Pareto: Carrying Coase Further’, Yale L.J. 100 (5), 1211-37.

Cihak, Herbert E. (2007), ‘The Help America Vote Act: Unmet Expectations?’, U. Ark. Little Rock L. Rev. 29 (4), 679-703.

Coase, R.H. (1981), ‘The Coase Theorem \& the Empty Core: A Comment', J.L. \& Econ. 24 (1), 183-87.

Demsetz, Harold (1969), ‘Information and Efficiency: Another Viewpoint’, J. L. \& Econ. 12 (1), 1-22.

Easterbrook, Frank H. (1982), 'Ways of Criticizing the Court', Harv. L. Rev. 95 (4), 802-32.

Elhauge, Einer R. (1991), ‘Does Interest Group Theory Justify More Intrusive Judicial Review?’, Yale L.J. 101 (1), 31-110.

Eskridge, William N. (1988), 'Politics Without Romance: Implications of Public Choice Theory for Statutory Interpretation', Va. L. Rev. 74 (2), 275-338.

Farber, Daniel A. and Philip P. Frickey (1987), ‘The Jurisprudence of Public Choice’, Tex. L. Rev. 65 (5), 873-927.

Farber, Daniel A. and Philip P. Frickey (1988), 'Legislative Intent and Public Choice’, Va. L. Rev. 74 (2), 423-69.

Glicksman, Robert L. and Richard E. Levy (2008), 'A Collective Action Perspective on Ceiling Preemption by Federal Environmental Regulation: The Case of Global Climate Change’, Nw. U. L. Rev. 102 (2), 579-648.

Hotelling, Harold (1929), ‘Stability in Competition’, Econ. J. 39 (153), 41-57.

Hovenkamp, Herbert (1990), ‘Legislation, Well-Being, and Public Choice, U. Chi. L. Rev. 57 (1), 63-116.

Jacobi, Tonja (2009), 'Competing Theories of Coalition Formation and Case Outcome Determination', Journal of Legal Analysis, 1 (forthcoming) (Jacobi 2009b)

Kornhauser, Lewis A. and Lawrence G. Sager (1993), ‘The One and the Many: Adjudication in Collegial Courts', Cal. L. Rev. 81 (1) 1-59. 
Levmore, Saul (1989), 'Parliamentary Law, Majority Decision Making, and the Voting Paradox', Va. L. Rev. 75 (5), 971-1044.

Levmore, Saul (2002), 'Ruling Majorities and Reasoning Pluralities’, Theoretical Inquiries Into Law 3 (1), 87-123.

Macey, Jonathan R. (1986), 'Promoting Public-Regarding Legislation Through Statutory Interpretation: An Interest Group Model’, Colum. L. Rev. 86 (2), 223-68.

McLean, Iain and Arnold B. Urken (1992), 'Did Jefferson or Madison Understand Condorcet's Theory of Social Choice?', Pub. Choice 73, 445-57.

Merrill, III, Samuel (1984), ‘A Comparison of Efficiency of Multicandidate Electoral Systems’, Am. J. Pol. Sci. 28 (1), 23-48.

Meyerson, Michael I. (2005), ‘The Irrational Supreme Court’, Neb. L. Rev. 84 (3), 895-961.

Mulroy, Steven J. (1999), 'Alternative Ways Out: A Remedial Road Map for the Use of Alternative Electoral Systems as Voting Rights Act Remedies’, N.C. L. Rev. 77 (5), 1867-1924.

Nash, Jonathan Remy (2003), ‘A Context-Sensitive Voting Protocol Paradigm for Multimember Courts’, Stan. L. Rev. 56 (1), 75-159.

Nurmi, Hannu (1983), ‘Voting Procedures: A Summary Analysis’, Brit. J. of Pol. Sci. 13 (2), 181-208.

Pildes, Richard H. and Elizabeth S. Anderson (1990), 'Slinging Arrows at Democracy: Social Choice Theory, Value Pluralism, and Democratic Politics’, Colum. L. Rev. 90 (8), 2121-2214.

Post, David G. and Steven C. Salop (1996), 'Issues and Outcomes, Guidance, and Indeterminacy: A Reply to Professor John Rogers and Others’, Vand. L. Rev. 49 (4), 1069-85.

Richie, Robert (2004), 'Instant Runoff Voting: What Mexico (and Others) Could Learn, Election L. J. 3 (3), 501-12.

Saari, Donald G. and Vincent C. Merlin (1996), 'The Copeland Method I: Relationships and the Dictionary', available at http://citeseerx.ist.psu.edu/viewdoc/summary?doi=10.1.1.38.4215.

Samuelson, Paul A. (1938), ‘A Note on the Pure Theory of Consumer’s Behaviour’, Economica 5 (17), 61-71.

Schepsle, Kenneth A. (1992), ‘Congress is a “They,” not an “It”: Legislative Intent as Oxymoron’, Int’l Rev. L. \& Econ. 12 (2), 239-56.

Schepsle, Kenneth A. and Barry R. Weingast (1981), 'Structure-induced equilibrium and legislative choice’, Pub. Choice 37 (3), 503-19.

Schepsle, Kenneth A. and Barry R. Weingast (1987), 'The Institutional Foundations of Committee Power', Am. Pol. Sci. Rev. 81 (1), 85-104.

Stearns, Maxwell L. (1994), ‘The Misguided Renaissance of Social Choice’, Yale L.J. 103 (5), 1219-93.

Stearns, Maxwell L. (1995), 'Standing Back from the Forest: Justiciability and Social Choice', Cal L. Rev. 83 (6), 1309-1413.

Stearns, Maxwell L. (1995), 'Standing and Social Choice: Historical Evidence’, U. Pa. L. Rev. 144 (2), 309-462. 
Stearns, Maxwell L. (1999), 'Should Justices Ever Switch Votes?: Miller v. Albright in Social Choice Perspective', Sup. Ct. Econ. Rev. 7, 87-156.

Stearns, Maxwell L. (2000), 'The Case for Including Marks v. United States in the Canon of Constitutional Law', Const. Comment. 17 (2), 321-39.

Stearns, Maxwell L. (2002), ‘The Condorcet Jury Theorem and Judicial Decisionmaking: A Reply to Saul Levmore', Theoretical Inquiries Into Law 3 (1), 125-50.

Stearns, Maxwell L. (2003), 'A Beautiful Mend: A Game Theoretical Analysis of the Dormant Commerce Clause Doctrine’, Wm. \& Mary L. Rev. 45 (1), 1-155.

Stout, Lynn A. (1992), 'Strict Scrutiny and Social Choice: An Economic Inquiry into Fundamental Rights and Suspect Classifications’, Geo. L.J. 80 (5), 1787-1834.

Tullock, Gordon (1981), ‘Why So Much Stability?’, Pub. Choice, 37 (2), 189-204.

Vasiljev, Sergei A. (unpublished manuscript April 1, 2008), 'Cardinal Voting: the Way to Escape the Social Choice Impossibility’, SSRN 1116545, available at http://ssrn.com/abstract=1116545.

Vickrey, William (1960), ‘Utility, Strategy, and Social Decision Rules’, Q. J. Econ. 74 (4), 507-35.

Wiley, Jr., John Shepard (1987), ‘Antitrust and Core Theory’, U. Chi. L. Rev. 54 (2), 556-89.

\section{$\underline{\text { Cases }}$}

Board of Regents v. Bakke, 438 U.S. 265 (1978).

Crawford v. Board of Education, 458 U.S. 527 (1982).

Hammer v. Daggenhart, 247 U.S. 251 (1918).

Immigration and Naturalization Service v. Chadha, 462 U.S. 919 (1983).

Lochner v. New York, 198 U.S. 45 (1905).

Marks v. United States, 430 U.S. 188 (1977).

New York v. United States, 505 U.S. 144 (1992).

Planned Parenthood of Southeastern Pennsylvania v. Casey, 505 U.S. 833 (1992).

Roe v. Wade, 410 U.S. 113 (1973).

United States v. Carolene Products Co., 304 U.S. 144 (1938).

Washington v. Seattle School District No. 1, 458 U.S. 457 (1982).

West Coast Hotel Co. v. Parrish, 300 U.S. 379 (1937).

$\underline{\text { Other }}$

Australian Electoral Commission, Electoral Backgrounder No. 17 (Oct. 2007), available at 
http://www.aec.gov.au/pdf/backgrounders/17/EB_17_Compulsory_Voting.pdf. 